\title{
Predator-mediated, non-equilibrium coexistence of tree-hole mosquitoes in southeastern North America
}

\author{
William E. Bradshaw ${ }^{1}$ and Christina M. Holzapfel ${ }^{2}$ \\ ${ }^{1}$ Department of Biology, University of Oregon, Eugene, OR 97403, USA \\ 2 Tall Timbers Research Station Tallahassee, FL 32312, USA
}

\begin{abstract}
Summary. Mosquito populations in tree holes in northern Florida $\left(30.6^{\circ} \mathrm{N}\right.$ lat.), USA are held below their carrying capacities by a self-limiting, cannabalistic predator. Within tree holes, extinctions and reinvasions are common; in the system as a whole, extinctions and immigrations occur without regard to community composition, tree-hole size or stability, or average number of species present. Little, if any, density-dependent development takes place. There is no evidence that the community ever reaches equilibrium, that competition is taking place, or that competition has been an important factor structuring this mosquito community. Rather, examination of related species in the same genera suggests that the principal determinants of their coexistence relate to the adaptations already possessed by each species at the time of their first encounter. Thus, unless experimentally demonstrated or reasonably inferred from circumstantial evidence, competition and coevolved niche shifts cannot be invoked to explain the coexistence of a diversity of species within a habitat type, no matter how circumscribed or discrete that habitat.
\end{abstract}

Competition has been frequently invoked as a force organizing communities. Certainly, competition does exist and it can be a factor in the composition and diversity of communities (Paine 1974; Dayton 1975; Brown et al. 1979; Connell 1961; Grant 1972). However, for an increasing number of examples, closer inspection of interspecific relationships reveals habitat specialization that minimizes competitive interaction (Cody 1966; Schoener 1974; Pianka 1969; Lubchenco and Menge 1978; Lounibos 1981). These specializations are often thought to have arisen as a result of competition in the past, selecting for niche shifts or "ecotopic specialization" (Pittendrigh 1950) which, in the present, are viewed as coevolved specializations. Part of the presumption of competition follows from the further, more basic assumption of communities at equilibrium (MacArthur 1972; Cody 1974; Diamond 1978), where all of the habitat's resources must be allocated among its inhabitants, leading to limiting similarities of species (Hutchinson 1959; MacArthur and Levins 1967; MacArthur 1972; Abrams 1975).

Competition for limiting resources is expected to be most immediate in a restricted habitat. Would, for example,

Offprint requests to: W.E. Bradshaw
Hutchinson (1959) have considered coexistence among corixids if Santa Rosalia had been the patron saint of a lake instead of a small limestone spring? One can easily rationalize coevolved niche shifts among species interacting over a broad and/or diverse habitat but what happens when habitats are small and circumscribed? To develop this question, we have considered the tree-hole mosquito fauna in southeastern United States.

Tree holes have a world-wide distribution, being common wherever there are mature stands of hardwood trees. Typically, these holes are formed between root buttresses or in arboreal crotches or as a result of decay after a branch has broken off. Whenever these tree-holes contain water, they also tend to contain a specific mosquito fauna (Keilin 1932; Kitching 1971, 1982; Corbet 1964; Jenkins and Carpenter 1946; Service 1965; Lounibos 1981, 1982). In north Florida, we located 115 water-filled holes in 11 species of hardwood trees; at one time or another over a year's period, all contained mosquitoes. These mosquitoes included seven species in as many genera (Fig. 1). Two species, Culex restuans Theobald and Culiseta melanura (Coq.), are normally considered ground-water mosquitoes; the other five prefer tree holes to alterante habitats (Jenkins and Carpenter 1946; Horsfall 1955). Of the latter 5 species, Toxorhynchites rutilus (Coq.) and Corethrella appendiculata Grabham are predominately carnivorous, Aedes triseriatus (Say) and Orthopodomyia signifera (Coq.) are filter-feeders and/or browsers, and Anopheles barberi (Coq.) is primarily a filter feeder but also a facultative carnivore (Petersen et al. 1969). We initially sought to determine the manner by which they could continue to coexist indefinitely in a habitat which averaged less than 3.01 in volume; and, in this paper, we show that the tree-hole mosquitoes do partition their habitat spatially and trophically. Further, we provide evidence that this habitat specialization has not evolved in response to competition; rather, the community is held below carrying capacity by predation and unoccupied subhabitats are still available.

\section{Materials and methods}

Study area

The Tall Timbers Research Station $\left(30.6^{\circ} \mathrm{N}, 84.2^{\circ} \mathrm{W}\right)$ is situated on a 1,200 hectare nature preserve along the northern edge of Lake Iamonia, Leon County, Florida. From 


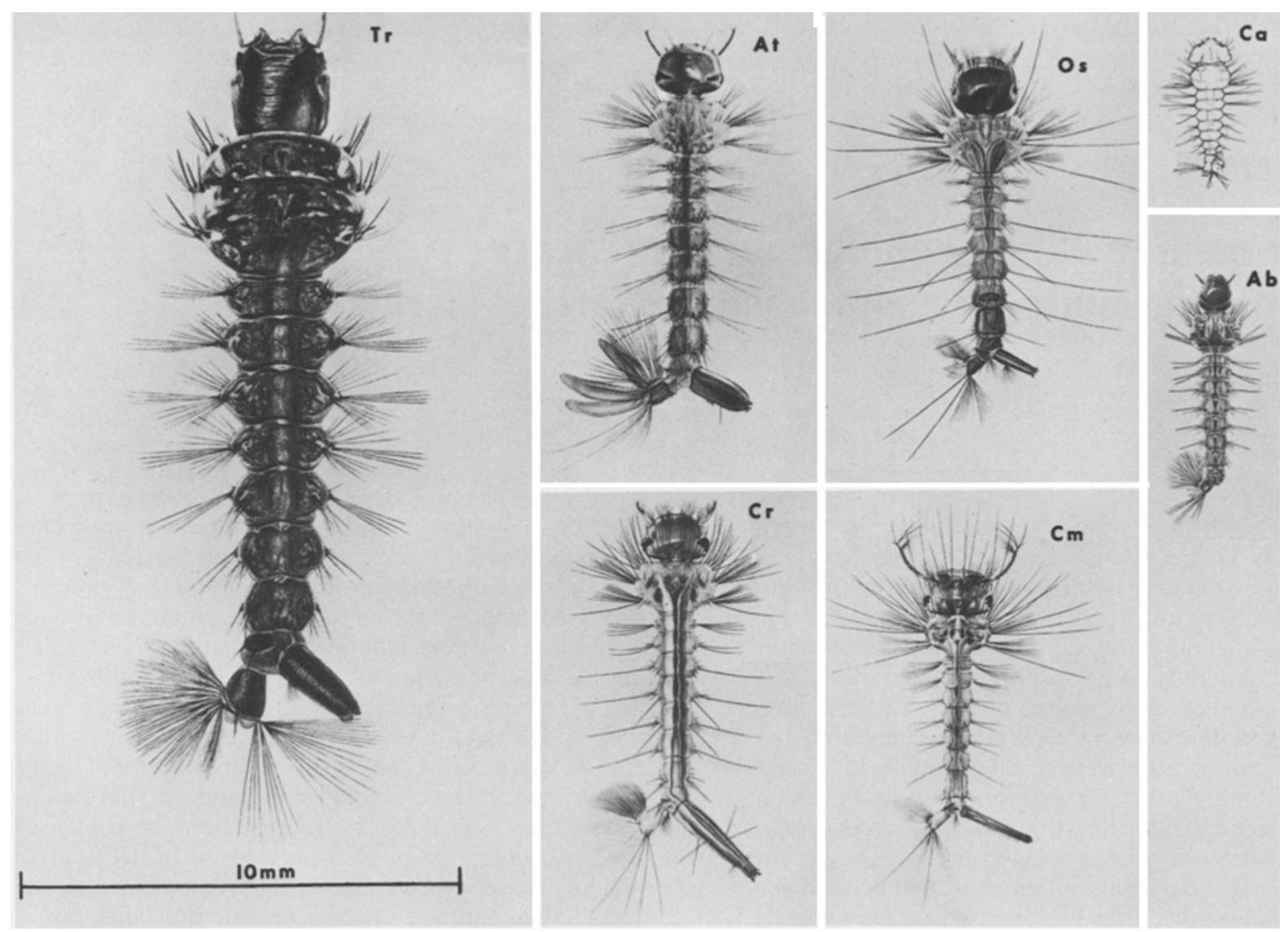

Fig. 1. Fourth instars of mosquitoes found in northern Florida tree holes drawn to scale. Tr Toxorhynchites rutilus; Os Orthopodomyia signifera; At Aedes triseriatus; Ab Anopheles barberi; Ca Corethrella appendiculata; $\mathrm{Cr}$ Culex restuans; Cm Culiseta melanura. All illustrations except $C$. appendiculata are taken from Howard et al. (1913) and are reprinted with permission from the Carnegie Institution of Washington

Lake Iamonia, the land rises from just under $100^{\prime}(30 \mathrm{~m})$ elevation to about $250^{\prime}(76 \mathrm{~m})$ in the northern portion (Fig. 2). The lake is bordered by mixed hardwood forests which form larger tracts in Woodyard and Fraction Hammocks and cover much of Hall, Gay's, and Sheep Islands. These forests consist primarily of sweet gum (Liquidambar styraciflua L.), live oak (Quercus virginiana Mill.), water oak (Q. nigra L.), beech (Fagus grandifolia Ehrh.), magnolia (Magnolia grandiflora L.), ironwood (Ostrya virginiana Mill.), tupelo gum (Nyssa sylvatica Marsh), holly (Ilex opaca Ait.), and pignut hickory (Carya glabra Mill.). Areas of mixed hardwoods located mainly along watercourses or around ponds (Fig. 2) also reticulate throughout Tall Timbers. The bulk of the preserve is covered by open fields or open piney woodlands. The latter are composed of mainly slash (Pinus ellottii Engelm.) or loblolly pine (P.taeda L.), often interspersed with hardwood trees. In the northwest portion of Tall Timbers, the open-woods hardwoods consist principally of mockernut hickory (Carya tomentosa Nutt.) and white oak (Q.alba L). Sprinkled throughout Tall Timbers are 0.25 acre $(0.041$ hectare) fire study plots whose tree composition depends upon both their nearness to water and the frequency with which they are burned. Excepting hardwood hammocks, forests adjoining water courses, and fire-study plots, the entire Tall Timbers Research Station is control-burned each year during the late winter-early spring.

\section{Tree holes}

Locating, sampling, and censusing. We located pans or rot holes (Kitching 1971), that contained water and mosquitoes at least once between October 1, 1977 and July 31, 1978. At regular intervals we examined and sampled the contents of these tree holes. We removed all fluid from small holes with a pipette and from larger holes by siphoning the contents with a $1.25 \mathrm{~cm}$ inside diameter hose. The samples were concentrated by filtering through a fine mesh (small enough to retain first instars of all but Corethrella appendiculata) aquarium net. Usually the siphon established a good suction and the contents of the hole flowed smoothly and rapidly; in those cases where the siphon did not flow freely, the water just taken from the hole was filtered through the same finemesh net and the filtrate used to rinse and re-siphon the hole. This procedure was repeated until we obtained a free-flowing siphon sample. Our sampling is therefore probably at least as efficient as that reported by Lounibos (1982) for his "original extract." Samples in quart $(0.951)$ plastic bags were carried to the laboratory where they were maintained in an incubator whose temperature had been set at the prevailing early morning tree-hole temperature. To census mosquitoes, we placed the sample into a $15 \times 22.5 \mathrm{~cm}$ plastic pan which was nested into a second pan filled with ice. This technique maintained sample temperature at or below that prevailing in the field 


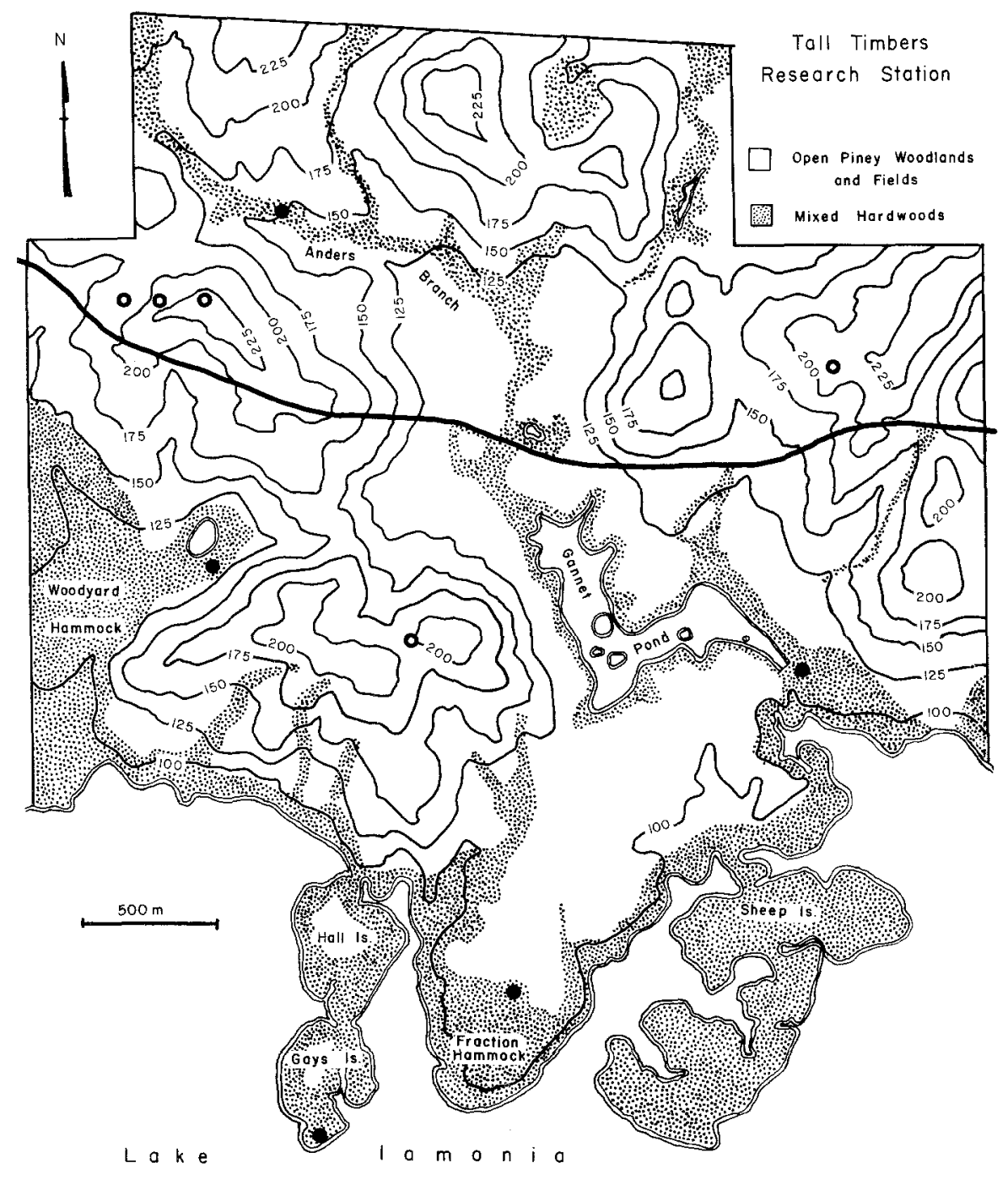

Fig. 2. Map of the Tall Timbers Research Station, Leon Co., Florida. Dots and circles relate to Table 2 showing the location of tree holes in the woods and isolated on open ridges, respectively which was especially important for larger samples which sometimes required $3-4 \mathrm{~h}$ to census. We counted the number of each instar of each species, discriminating the species of first and, sometimes, second instars under a dissecting microscope. After censusing, we placed the samples back in the incubator and subsequently returned them to their respective holes. Samples were taken, censused, and returned on the same day, usually within a 3-5 but no more than $8-9 \mathrm{~h}$ period.

Between February and December, 1978, we made 19 censuses of the tree-hole system at approximately 2-week intervals. We chose this time frame since our observations indicated it was slightly less than a generation time for Aedes triseriatus, the fastest developing species we examined. Thus, while successive censuses were likely to encounter some of the same individuals, we were unlikely to miss any species which might occupy a given hole.

Originally, we identified 79 holes but as we censused these, some dried up permanently and we located others. At the same time, it became clear that we could not continue indefinitely to census every hole. Consequently, we censused all known holes during censuses $4-5$ and then reduced our basic number to 44 of which 9 dried up permanently sometime during the year, leaving us with 35 holes censused for the first 17 censuses. These holes were selected from the larger group to assure a wide range in host tree species and in hole size from large to small. By the 17th census, a long drought had dried up all but one hole in mid-October (Fig. 3). Apart from spot checks, censusing was then suspended until December when there was sufficient rain to generate standing water in the tree holes. Due to logistical problems, we sampled only 19 holes in December for censuses 18 and 19.

For each census, we checked the hole for the presence of standing water; if there was no standing water, we scored the hole as dry, even if the substrate was moist. If the hole contained standing water, we drained and measured the volume of water contained in the hole. This regime eventually provided us with the frequency that a given hole was dry during the year.

Identification of species. We experienced no difficulty in discriminating Toxorhynchites rutilus, Orthopodomyi signifera, Aedes triseriatus, Anopheles barberi, Corethrella appendiculata, Culex restuans, or Culiseta melanura at any stage of their development although our sampling technique routinely missed first and second instars of Corethrella appendiculata. It was possible that we might encounter Aedes hendersoni Cockerell (Zavortink and Belkin 1979) or Orthopodomyia alba Baker but we took precautions to contend with 


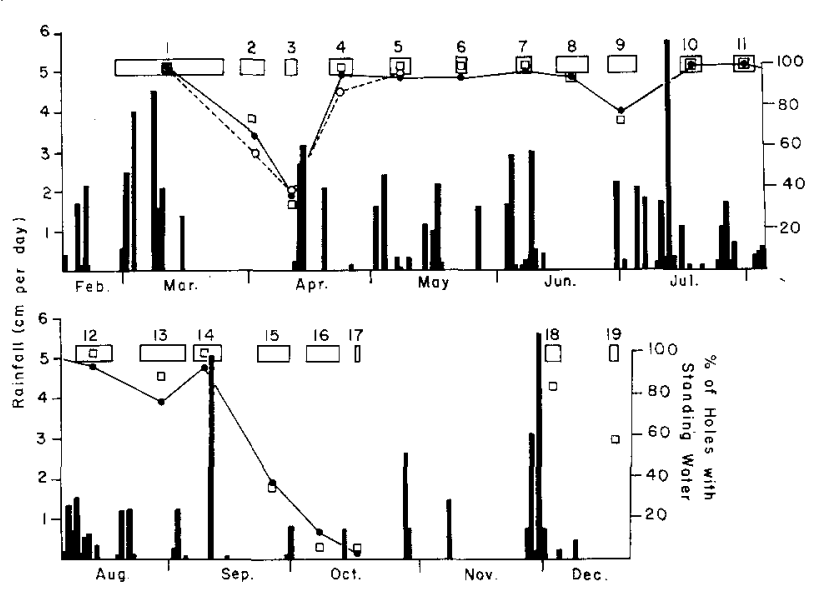

Fig. 3. Rainfall pattern at Tall Timbers in 1978. The open rectangles at the top of the figure show the time and duration of the census indicated by the number above it. Percentage of holes with standing water is broken down into 79 holes for censuses 1-5 (open circles), 35 holes for censuses 1-17 (solid circles), and 19 holes for censuses 1-19 (open squares)

that possibility. We periodically checked smaller subsamples for the presence of $A$. hendersoni, especially from tree-hole \#146 which, at $3.97 \mathrm{~m}$ above the ground, was the highest hole we surveyed and most likely to contain A. hendersoni (Sinsko and Grimstad 1977; Scholl and DeFoliart 1977). As discriminating characters, we looked first for the lighter color, then equal-length anal papillae, and finally, the detached acus of the A. hendersoni larvae (Truman and Craig 1968; Zavortink 1972; Grimstad et al. 1974). At no time did we observe any larvae resembling $A$. hendersoni. In addition, L.P. Lounibos (personal communication) made a search in 1981 for A. hendersoni at Tall Timbers, including tree holes $4-5 \mathrm{~m}$ above the ground, without success. We therefore conclude that, at most, $A$. hendersoni is rare at Tall Timbers and that our samples contained predominantly or exclusively $A$. triseriatus. Although Zavortink (1968) does not list Florida within the range of Orthopodomyia alba, we also checked for the presence of this species in our samples. While we cannot for certain exclude the presence of $O$. alba among the younger instars, we found no fourth instars of this species, and therefore assumed that our samples contained exclusively $O$. signifera.

Tires. During February, 1978, we hung 10 tires $1.5 \pm 0.2 \mathrm{~m}$ from the ground in Woodyard Hammock (Fig. 2). We immediately seeded these tires with tree-hoie slop which we had gathered from a single local tree and heated to $80^{\circ} \mathrm{C}$ to kill the insects present. The amount of slop was adjusted so that the light of a flashlight could just penetrate to the top of the detritus layer in the tire. During the experimental periods covered in this paper, we maintained at least $15 \mathrm{~cm}$ of standing water in each tire, either by natural rainfall or, during dry periods, by the addition of unchlorinated well water.

Biomass. Total mosquito biomass or the biomass of any one species was calculated from the mean dry-weight of each instar of each species (Bradshaw and Holzapfel, unpublished).

\section{Results}

\section{Seasonal abundance}

To assess tree-hole population size over time, we examined the census data from only those 35 holes for which we had consecutive samples from March through October, 1978. Figure 4 shows the number or total biomass of each species pooled for each of 17 censuses. From the overwintering generation until the major drought starting in late September, $T$. rutilius and $O$. signifera generally maintained constant population biomass throughout the year while biomass of A. triseriatus and $A$. barberi generally declined after the spring. Population biomass of C. appendiculata declined during April, May, and June but rose again in July, August, and September. C. restuans appeared during the first census, peaked in late March, declined to one individual in May, and was not observed thereafter. C. melanura appeared only sporadically from March to June and was also not observed thereafter.

Between February and December, 1978, we located 115 individual holes which we examined 1-19 times each. If the hole contained water, it was censused. Thus, some of our results report repeat censuses on the same holes. Where such repeat censuses occur, we term them wet-holes, akin to hole-censuses or hole-samples; otherwise, the census data given are for individual tree holes or the mean of a series of censuses of individual holes. Our 1978 censuses yielded 772 wet-holes and 7 species of mosquitoes; of these 7 , $C$. restuans and C.melanura were restricted to the spring (Fig. 4) or the period immediately following the heavy rains in November. C. restuans occurred in only 25 and C. melanura in only 15 of the 772 wet-holes. By contrast, we encountered the other 5 species in every census period in a wide variety of holes. Consequently, the remainder of the paper emphasizes relationships among the other 5 species, namely T. rutilus, A. triseriatus, O. signifera, A. barberi, and C. appendiculata.

\section{Tree-hole size, permanence, and mosquito abundance}

While the above results provide a picture of system-wide seasonal population trends, they say little about events occurring in single tree holes and how these events relate to the species found therein. Starting with this section we shall consider the physical factors of habitat size (tree-hole capacity, the maximum volume observed in a given hole during 1978) and permanence (proportion of censuses during which a given hole contained standing water) through time, continue with the effect of these factors on species richness, and then examine the associations and biotic interactions of the mosquitoes themselves.

Tree-hole capacity was a good predictor of total mosquito biomass but the constituent species varied with respect to their relationship to tree-hole volume (Fig. 5). Mean biomass of $T$. rutilus, $O$. signifera, and $A$. barberi was proportional to tree-hole capacity but biomass of $A$. triseriatus and C. appendiculata was not. Tree-hole capacity was also a good predictor of tree-hole permanence (Fig. 6), the larger holes having a greater probability of containing standing water. Taken together, these results suggest that A. triseriatus is relatively more abundant in the smaller, more ephemeral holes while T.rutilus, O. signifera, and A. barberi are more abundant in the larger, more permanent holes. 

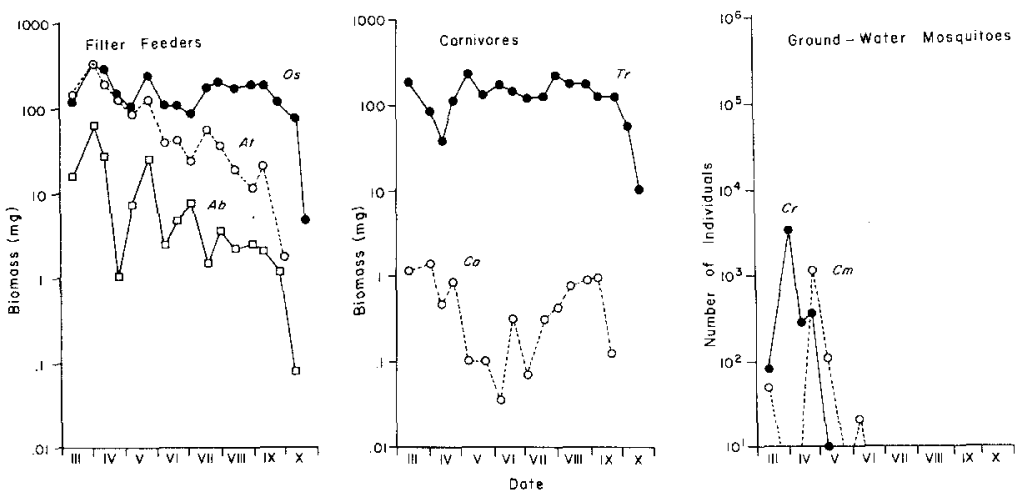

Fig. 4. Standing crop of each species in 35 holes sampled 17 times from February to October, 1978. Each circle represents the mid-point of a given census whose total duration is shown in Fig. 3

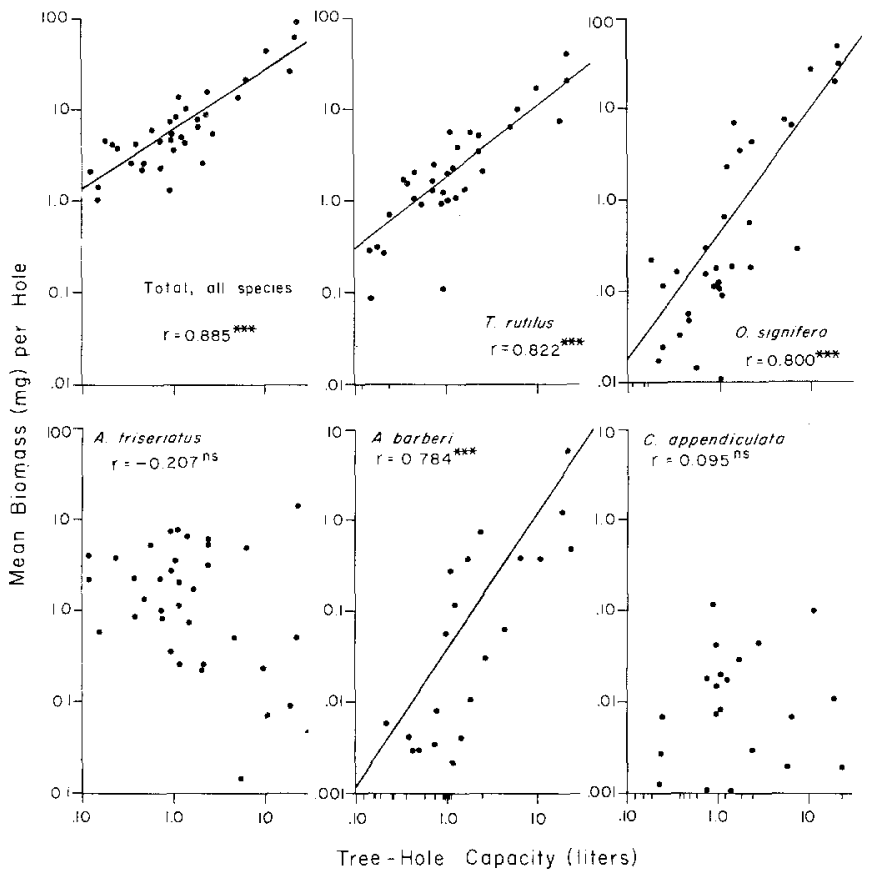

Fig. 5. Relationship between tree-hole capacity and the average biomass of mosquitoes found in tha hole if it had standing water. Data are from the 35 holes censused 17 times between February and October 1978. Small hash marks on the horizontal axis indicate holes in which the given species was never found; these holes were not included in the correlation. ns, non-significant correlation; ***, significant correlation, $P<0.001$

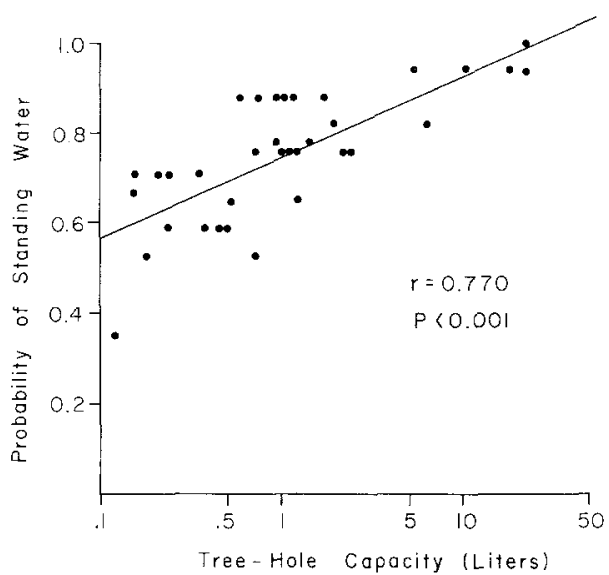

Fig. 6. Effect of tree-hole capacity on permanence of 35 holes censused 17 times between February and October 1978 (total of 447 wet-holes)

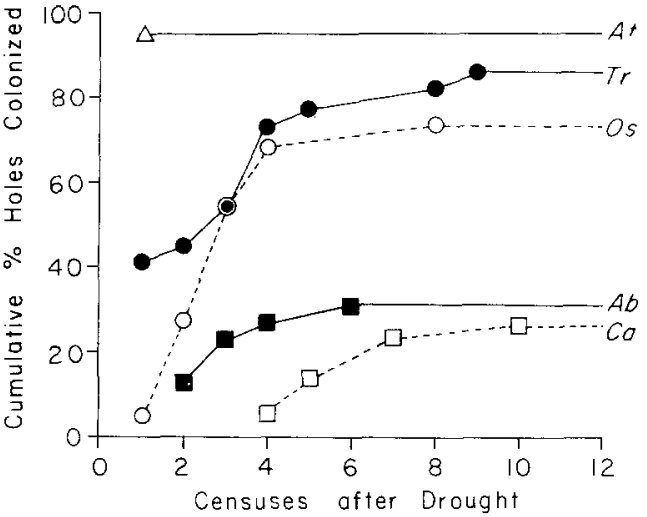

Fig. 7. Cumulative recolonization of the 23 holes which had dried up by the third census

The eggs of $A$. triseriatus, unlike those of the other treehole mosquitoes considered here, are laid on the side of the hole, above the water, and are able to withstand an indeterminate period of drought (Jenkins and Carpenter 1946). Thus, following a drought and subsequent rainfall, A. triseriatus can hatch immediately while the other treehole mosquitoes must first relocate holes and then oviposit into them. Following a drought, $A$. triseriatus larvae should therefore appear immediately upon tree-hole filling whereas the appearance of the other species should be delayed.

To investigate differences in colonizing ability, we monitored the reinvasion of larvae following both a short(2-4 week) and long- (6-10 week) drought. Of the 35 holes followed for 17 censuses, 23 of them dried up by the third census. Figure 7 shows the cumulative frequency of these holes recolonized after the short drought. A. triseriatus appeared in $95 \%$ of the holes in the first census following the drought; T. rutilus appeared in $40 \%$ of the holes in the first census and $40 \%$ more within four censuses. $O$. signifera did not appear as rapidly as $A$. triseriatus or $T$. rutilus but did eventually occur in $73 \%$ of the holes. A. barberi was more retarded in its appearance, never to invade more than a third of the previously dry holes.

The longer drought from September to December, 1978, resulted in the drying up of all holes for 6-10 weeks. After this long drought, we censused 19 of the holes, including both drought-prone holes which had dried up by the second or third census and drought-resistant holes, one of which was the only hole persisting into the seventeenth census. Figure 8 shows the standing crop (cumulative biomass) of mosquitoes in these holes both before and after the drought. As previously (Fig. 4), the standing crop of T. rutilus and 


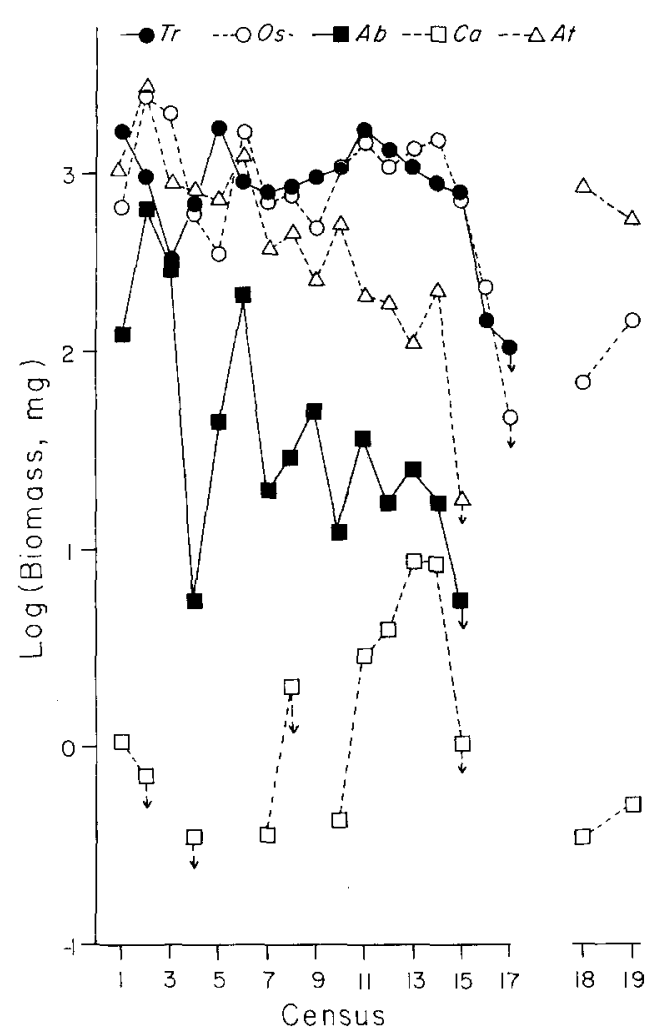

Fig. 8. Total standing crop of each species in 19 holes censused 19 times between February and December 1978. The gap between censuses 17 and 18 represents the dry period from October to December (shown in Fig. 3) during which time all holes were dry

$O$. signifera remained consistently high until the tree-holes commenced drying up in the 16-17th census (Fig. 8) while the standing crop of $A$. triseriatus and $A$. barberi exhibited a continual decline throughout this period. After the long drought, however, we did not observe T. rutilus or A. barberi in any of the holes. A. triseriatus not only reappeared rapidly after the drought but did so at levels above those observed during the mid- to late summer when it was continually raining. Although $O$. signifera did reappear after the long autumnal drought, it did so in only 3 holes and at a level more characteristic of the drought-stressed holes in September than the regularly water-filled holes earlier in the season.

The above observations indicate that $A$.triseriatus is least affected by drought of long or short duration. Indeed, the predominance of $A$. triseriatus may be favored by an especially long drought. T. rutilus rapidly appears in holes following a drought of short but not long duration. O. signifera appears in holes after both short or long droughts, albeit more slowly than $T$. rutilus after a short drought and at greatly reduced levels after a long one. $A$. barberi would seem to be the least drought resistant of any species, appearing slowly after a short drought and not at all after a long one.

\section{Species richness}

The greater abundance of T.rutilus, O. signifera, and A. barberi in previously dry holes (Fig. 7) suggests that the average number of species in a tree hole may be associated with its size and permanence. To illustrate the effects of
Table 1. Extinctions and immigrations in 35 holes censused 17 times between February and October, 1978

\begin{tabular}{|c|c|c|c|c|c|c|}
\hline $\begin{array}{l}\text { Number of occurrences } \\
\text { per hole per census }\end{array}$ & 0 & 1 & 2 & $3+$ & mean & $\begin{array}{l}\chi^{2} \text { with } \\
3 \text { de- } \\
\text { grees of } \\
\text { freedom }\end{array}$ \\
\hline Observed immigrations & 227 & 147 & 35 & 4 & \multirow[t]{2}{*}{0.554} & \multirow[t]{2}{*}{$4.15^{\text {ns }}$} \\
\hline Expected from Poisson & 237 & 132 & 36 & 8 & & \\
\hline Observed extinctions & 234 & 139 & 38 & 2 & \multirow[t]{2}{*}{0.535} & \multirow[t]{2}{*}{$4.87^{\mathrm{ns}}$} \\
\hline Expected from Poisson & 242 & 129 & 35 & 7 & & \\
\hline
\end{tabular}

size and permanence of habitat on species richness, we subdivided the tree holes into two categories: those which did not dry up during the spring drought and remained wet during both censuses, two and three ( 12 holes), and those which dried up during either or both of these censuses ( 23 holes). Figure 9 shows that while there was a positive correlation between species richness and size in both subpopulations, the slope relating species richness to tree-hole volume was steeper for the less than for the more permanent holes (analysis of covariance on log-transformed data: $\left.\mathrm{F}_{1,31}=6.64 ; P<0.05\right)$. These data suggest that the effect of size and permanence of habitat are not independent in their effects on species richness; rather, size becomes a more reliable predictor of species richness as the frequency of disturbance (drying) increases.

Greater species richness might result from lower average extinctions in or higher average immigrations into the larger, more stable holes. To consider this possibility, we examined the extinctions and immigrations in the 35 holes censused above. For each hole, starting with the second census, we counted as an extinction any species missing in the current census which had been present in the previous census and as an immigration any species which had been absent in the previous census that was present in the current census. We did not score dry tree holes as extinctions; rather, we used as a basis of comparison the most recent census when that hole had been wet. Using these criteria, we found no significant correlations between extinctions per hole $(r=$ $-0.116, P>0.05 ; r=0.135, P>0.05$ ) or immigrations per hole $(r=-0.028, P>0.05 ; r=-0.266, P>0.05)$ and either tree-hole permanence or tree-hole volume, respectively. In the 413 wet-holes from the second to seventeenth census, there was an average of 0.554 immigrations and $0.535 \mathrm{ex}-$ tinctions per hole. The pattern of these events showed no significant departure from random expectation (Table 1).

To determine the effects of tree-hole isolation on species turnover, we selected 5 holes on the top of ridges in open piney woodlands. These holes were the most isolated from any nearby woods or other tree holes of any we sampled. We then matched these 5 holes according to volume and times wet during the year with 5 holes within larger, wooded areas (Table 2). Two-way analysis of variance revealed a highly significant difference in mean number of species among holes. Therefore, we were examining a group of holes similar to the larger population considered earlier (Fig. 9). There were, however, no significant differences in number of immigrations or extinctions either among holes or between the isolated holes and those in the woods; nor was there a significant difference in mean number of species between the isolated trees and those in the woods. Thus, 
Table 2. Effects of tree-hole isolation on immigrations, extinctions, and number of species during 17 censuses between February and October, 1978. In Fig. 2, isolated holes are shown by o, holes in woods by

\begin{tabular}{|c|c|c|c|c|c|c|c|c|c|c|c|}
\hline \multicolumn{6}{|c|}{ Isolated Holes } & \multicolumn{5}{|c|}{ Holes in Woods } & \multirow[b]{2}{*}{$\overline{\mathrm{S}}$} \\
\hline $\begin{array}{l}\text { hole } \\
\text { number }\end{array}$ & $\begin{array}{l}\text { mean } \\
\text { volume }\end{array}$ & $\begin{array}{l}\text { times } \\
\text { wet }\end{array}$ & $\mathrm{Imm}$ & Ext & $\overline{\mathrm{S}}$ & $\begin{array}{l}\text { hole } \\
\text { number }\end{array}$ & $\begin{array}{l}\text { mean } \\
\text { volume }\end{array}$ & $\begin{array}{l}\text { times } \\
\text { wet }\end{array}$ & $\mathrm{Imm}$ & Ext & \\
\hline 172 & 0.07 & 6 & 1 & 1 & 0.8 & 182 & 0.11 & 11 & 3 & 3 & 1.4 \\
\hline 133 & 0.14 & 12 & 7 & 7 & 2.0 & 153 & 0.11 & 12 & 2 & 2 & 1.7 \\
\hline 187 & 0.14 & 9 & 3 & 3 & 1.8 & $193 \mathrm{H}$ & 0.29 & 9 & 5 & 4 & 1.6 \\
\hline
\end{tabular}

Two-way analyses of variance

\begin{tabular}{llll} 
& Immigration & Extinction & Mean number of species, $\overline{\mathrm{S}}$ \\
\hline Between holes & $\mathrm{F}_{4,9}=2.04^{\mathrm{ns}}$ & $\mathrm{F}_{4,9}=2.21^{\mathrm{ns}}$ & $\mathrm{F}_{4,9}=30.93, P<0.01$ \\
Between sites & $\mathrm{F}_{1,9}=0.01^{\mathrm{ns}}$ & $\mathrm{F}_{1,9}=0.10^{\mathrm{ns}}$ & $\mathrm{F}_{1,9}=0.36^{\mathrm{ns}}$ \\
\hline
\end{tabular}

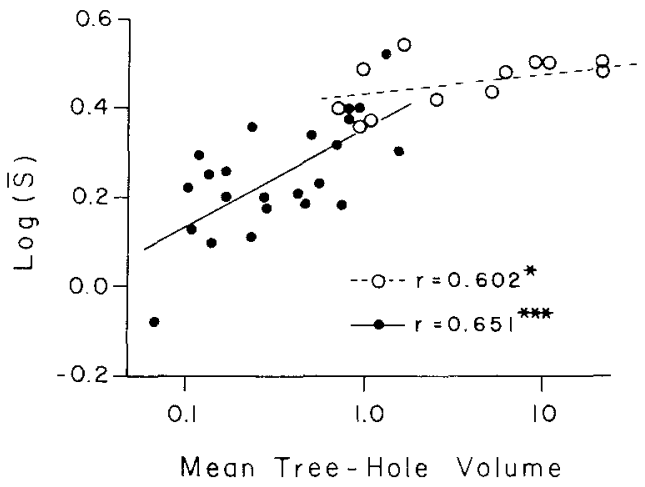

Fig. 9. Mean number of species observed per hole with standing water among 35 holes censused 17 times from February to October 1978: Mean number of species predicted from size broken down into $\left(--\mathrm{O}_{--}\right)$more and less $(\longrightarrow-)^{-}$permanent holes. Mean tree-hole volume is the average volume (liters) of standing water

the holes along the ridges and the matching holes in the woods do not differ from the total set of 35 holes with respect to the relationship between volume/permanence and species number. What the selected holes do point out is the apparent homogeneity of species turnover among all the tree holes at Tall Timbers, regardless of their size, permanence, or degree of isolation.

\section{Association of species}

The previous sections have considered general population trends and the interaction of species with their physical environment. We now turn attention to the interaction of the constituent tree-hole mosquitoes with each other. We shall first examine associations between species followed by an analysis of crowding and its density-dependent consequences and, finally, the impact of predation on this system.

To examine the association among species, we used techniques of pair-wise association based on presence-absence (Pielou 1977; pp 208-211) and factor analysis. Our census routine described above yielded 772 wet-holes but was designed to minimize the probability that we would miss any one generation completely. We were interested in temporal

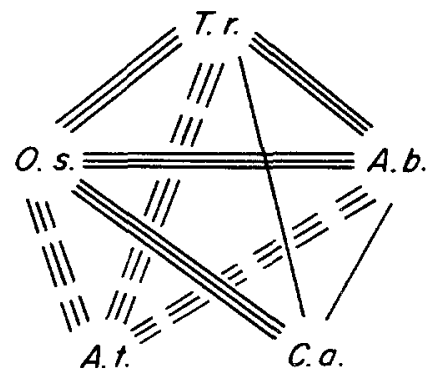

Fig. 10. Association between species during the overwintering (census 1), first summer (census 5), and mid-summer (census 10) generations. Positive associations are indicated by solid lines, negative associations (repulsions) by dashed lines. A single line designates a significant association $(P<0.05)$; a triple line represents a very highly significant association $(P<0.001)$

dynamics of the community as well as composition at any one time and very intentionally used a sampling with replacement technique. In so doing, we likely sampled the same individual more than once; hence, the species distribution found during a given census is not independent of previous censuses. For association analysis, we therefore selected three censuses: the first census ( 79 holes) represented the overwintering community; the fifth census (92 holes) represented the first summer generation and commenced 6 weeks after the end of the first; the tenth census (56 holes, 41 regularly censused plus 15 new ones, discovered in the interim) began 9 weeks after the end of the fifth census and thus provided ample time for even the youngest members of the fifth census to mature and leave the hole. By this procedure, we chose censuses with the largest number of holes and with the maximum time and variety of holes between censuses. Included in our analyses were all holes during the census (1) which contained standing water and (2) in which we found tree-hole mosquitoes during at least one of the 19 total censuses.

Pair-wise association analysis based on presenceabsence data in 227 wet-holes revealed strong positive associations among $T$. rutilus, $O$. signifera, A. barberi, and, to a lesser extent, $C$. appendiculata, and strong negative associations of $A$.triseriatus with T. rutilus, $O$. signifera, and A. barberi (Fig. 10). 
Table 3. Correlations (factor loadings) between original variables (biomass or numbers of individuals) and rotated factor scores for censuses 1,5 , and 10 combined ( 227 wet-holes)

\begin{tabular}{lrrrrr}
\hline & \multicolumn{2}{c}{ Biomass } & & \multicolumn{2}{c}{ Numbers } \\
\cline { 2 - 3 } & Factor 1 & Factor 2 & & Factor 1 & Factor 2 \\
\hline T. rutilus & 0.859 & -0.107 & & 0.856 & -0.154 \\
O. signifera & 0.778 & 0.014 & & 0.870 & 0.053 \\
A. triseriatus & -0.123 & 0.834 & & 0.000 & 0.988 \\
A. barberi & 0.767 & 0.255 & & 0.824 & 0.191 \\
C. appendiculata & 0.156 & 0.569 & 0.056 & -0.001 \\
\hline
\end{tabular}

In addition to pair-wise association, we subjected both number and biomass of mosquitoes from the same samples from censuses 1, 5 and 10 to factor analysis (Nie et al. 1975, Ch. 24). Factor analysis is especially useful when there are inter-correlations among variables, such as those among T. rutilus, $O$. signifera, and $A$. barberi in the results above (Fig. 10). A fundamental assumption of factor analysis is that these inter-correlations result from some underlying regularity in that data which, in biological terms, might in turn be ascribed to some common causative agent. While factor analysis does not identify this causative agent, it does cluster input variables into composite variables or factors which have the property of being orthogonal (uncorrelated with one another). Thus, the number of factors extracted provides a clue to the number of underlying causative agents while the correlations (factor loadings) between the original variables and the composite factors provide an indication of which variables are responding to these agents.

In the present case, factor analysis of both mosquito numbers and biomass resulted in the extraction of two factors (Table 3). Factor analysis of mosquito biomass and numbers revealed close correlations of the first factor with $T$. rutilus, $O$. signifera, and $A$. barberi, and a close correlation between the second factor and $A$. triseriatus. A moderate correlation between the second factor and $C$. appendiculata was observed only for the biomass data. Thus, factor analysis confirmed earlier inferences from tree-hole permanence (Figs. 5, 6) and pair-wise association (Fig. 10) that $T$. rutilus, $O$. signifera, and $A$. barberi comprise one subcommunity and $A$. triseriatus comprises a second, while the position of $C$. appendiculata appears intermediate between the two.

\section{Intra- and interspecific crowding}

The data in Fig. 10 and Table 3 suggest relationships based on presence-absence of species or covariation of population sizes without regard to habitat size, even though the latter is clearly an important determinant of population size (Fig. 5). Indicators of competition or prey limitation by predators relate more to the density of potential competitors or prey encountered than their total abundance. We therefore compared densities using Lloyd's (1967) indices of mean intra- and interspecific crowding per unit resource (Rathcke 1976; Hurlbert 1978), in this case, tree-hole volume. Lloyd's indices are especially tractable for discrete habitats and are readily interpretable as the mean number of species $y$ encountered per liter of tree-hole volume by the average individual of species $x$. If $x_{\mathrm{i}}$ is the number of individuals of species $x, y_{\mathrm{i}}$ the number of individals of

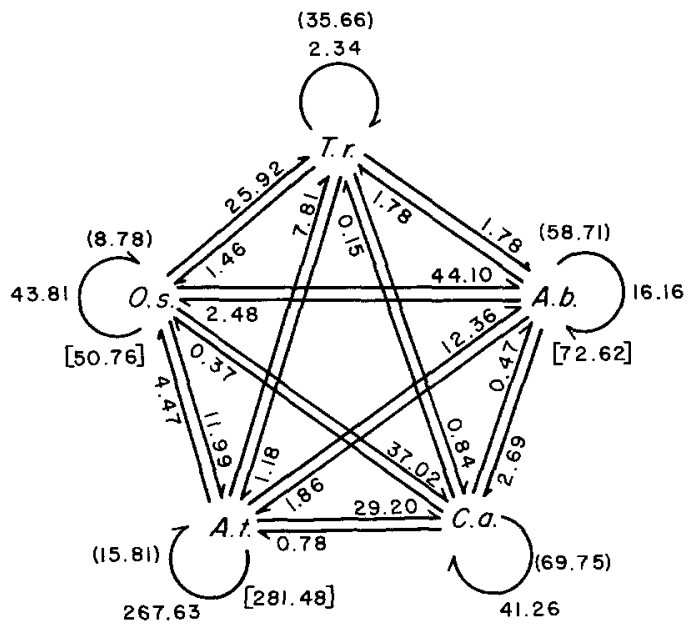

Fig. 11. Mean intra- and interspecific crowding per liter of actual tree-hole volume in 35 holes censused 17 times between February and October, 1978. Straight arrows show extent of interspecific crowding where $y \rightarrow x$ is the crowding of $y$ on $x$. Circular arrows designate intraspecific crowding. Numbers in parentheses indicate the total numbers of individuals of all other species encountered per liter by an individual of a given species; numbers in brackets indicate the total crowding per liter, including intra- and interspecific of filter feeders on the given species

species $y$, and $v_{\mathrm{i}}$ the actual volume of water in the ith tree hole, then mean interspecific crowding of $x$ by $y$ is given by $\Sigma \frac{x_{\mathfrak{i}} y_{\mathrm{i}}}{v_{\mathrm{i}}} / \Sigma x_{\mathrm{i}}$ and mean intraspecific crowding by the same formula but substituting $\left(x_{\mathrm{i}}-1\right)$ for $y_{\mathrm{i}}$.

Figure 11 summarizes intra- and interspecific crowding. Several patterns emerge from these relationships. (1) The predators, $T$. rutilus and $C$. appendiculata, both encounter a higher density of potential prey (all species) than they do each other or themselves. (2) Both T. rutilus and C.appendiculata encounter more $O$. signifera per unit volume than $A$. triseriatus. (3) The most abundant prey, $O$. signifera and $A$.triseriatus, experience far greater intra- than interspecific density. (4) $A$. barberi is the only filter feeder that encounters greater inter- than intraspecific density. These observations suggest, but do not show, that $T$. rutilus and $C$. appendiculata encounter abundant prey, that $O$. signifera and $A$.triseriatus are more likely to be self-limited, and that $A$. barberi may be more limited by other, competing filter feeders.

\section{Density-dependent development of filter feeders}

The co-habitation of a finite space and the data in Fig. 11 invite speculation into the probability of density-dependent constraints. Density-dependence may be intraspecific, interspecific, or a combination of both. To assess if the levels of crowding observed in Fig. 11 impose density-dependent constraints upon the mosquitoes in tree holes at Tall Timbers, we examined pupal production in the 35 holes censused from February to October, 1978 (Fig. 12). Most of the annual pupation of $A$. triseriatus and $A$. barberi took place in late March and early April (censuses 2-3) and thus resulted from overwintering generations. Both T. rutilus and $O$. signifera exhibited sustained production of pupae up until the drought commencing in September (Fig. 3). We therefore broke our analyses into three sections: pupal 


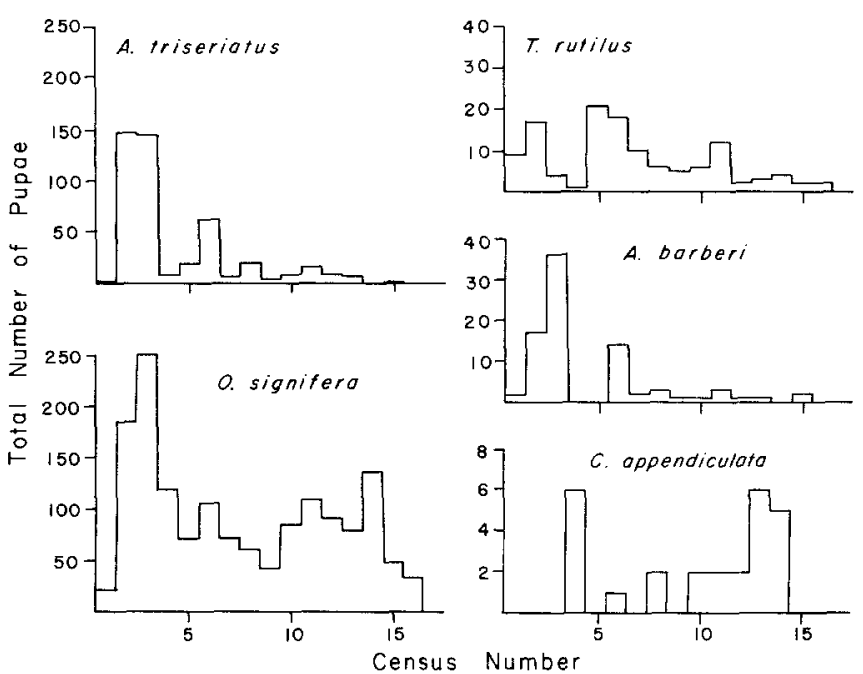

Fig. 12. Total numbers of pupae observed for each species during each of 17 censuses

production over (1) the entire February-October period, (2) the first five censuses representing primarily the overwintering and first summer generations, and (3) censuses $6-14$, representing summer generations before the onset of the drought.

In laboratory cultures of mosquitoes, increased larval density results in both longer larval development and reduced pupation success (Moore and Fisher 1969; Gilpin and McClelland 1979; Moeur and Istock 1980; Istock et al. 1975; Fish and Carpenter 1982). Hence, at any given time in nature, density-dependent development should be apparent from the relative abundance of pupae with respect to the total conspecific biomass. We therefore used pupae per $\mathrm{mg}$ of a given species in a tree hole as a criterion of emergence success and as a measure of density-dependence. We then performed step-wise regression of pupae per $\mathrm{mg}$ in the current census on three predictor variables: density (mg/ liter of actual tree-hole volume) of conspecifics, density of predators (both T.rutilus and C.appendiculata), and density of potentially competing filter feeders. The three variables were taken from the current and previous censuses, totalling six independent variables in all. To enter into the regression the criterion species must have been pres-

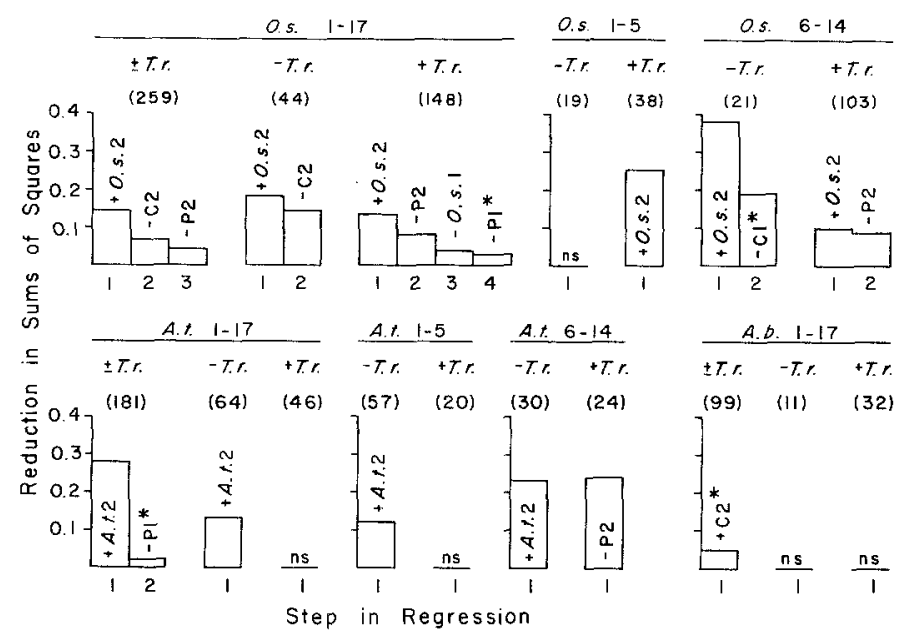

ent in the current census. The interval between censuses was greater than the duration of any pupal stage at prevailing temperatures. Thus, even though successive samples are not entirely independent as larvae censused at one time could re-appear as larvae or pupae during the next census, the lack of pupae at persistant high densities would indicate density-dependent constraints while the presence of pupae under the same conditions would indicate the lack of such constraints. Using these criteria, a positive correlation between pupation and a predictor variable indicates a beneficial effect while a negative correlation indicates a deleterious effect of competitors or predators.

Figure 13 shows the reduction in sums of squares (coefficient of determination, or the proportion of variation in pupation explained by regression) for successive significant steps of each regression. For all 17 censuses or in the absence of $T$.rutilus at any time of year, pupae per $\mathrm{mg}$ of A.triseriatus correlated positively with intraspecific density. In the presence of T. rutilus, pupation was correlated only with predator density in the current census and even then, only later in the year. There is therefore no evidence that $A$. triseriatus experiences either intra- or interspecific competitive pressure although predation has a significant effect on pupation at a time when populations of A. triseriatus are declining (Fig. 4).

For all 17 censuses pupae per mg of $O$. signifera was positively correlated with intraspecific density and negatively correlated with competitor and predator densities, all in the current census (Fig. 13). In the absence of T. rutilus, these same relationships, except for the effect of predation, still persisted. In the presence of T. rutilus, pupation by $O$. signifera was positively correlated with intraspecific density in the current census but negatively correlated with predator density in both the current and previous census but negatively correlated with predator density in both the current and previous census and with competitor density in the previous census. Breaking the censuses into spring (Cen. 1-5) and summer (Cen. 6-14) revealed positive correlations between pupation per $\mathrm{mg}$ of $O$. signifera and intraspecific density at both times but negative correlations between (1) pupation and competitor density in the absence of T. rutilus and (2) pupation and predator density in the presence of $T$. rutilus only later in the year. There is thus little evidence that intraspecific density limits pupation in $O$. signifera but some evidence exists that interspecific

Fig. 13. Step-wise multiple regression of pupae per mg total biomass of $O$. signifera, $A$. triseriatus, or $A$. barberi on the density of its own species, of predators ( $T$. rutilus and C. appendiculata), and other filter feeders in both the current and previous censuses (total of six independent variables). All independent variables returned presented a highly significant reduction in sums of squares (increase in coefficient of determination, $P<0.01$ ) except $*, P<0.05$, and ns, not significant. The species and number of censuses considered are shown above each set of bar graphs. $\pm T . r$. , density of $T$. rutilus not taken into account; + T.r., only those holes with $T$. rutilus in both the current and previous censuses are considerd; - T.r., only those holes with T. rutilus absent in both the current and previous censuses are considered. Numbers in parentheses indicate the number of wet-holes involved. Within or above each bar is shown the variable returned for that step in regression, with a + for a positive correlation and $\mathrm{a}-$ for a negative correlation; $\mathrm{C}$,

heterospecific filter feeders; $\mathrm{P}$, predators; 1 or 2 indicates the previous or current census, respectively 

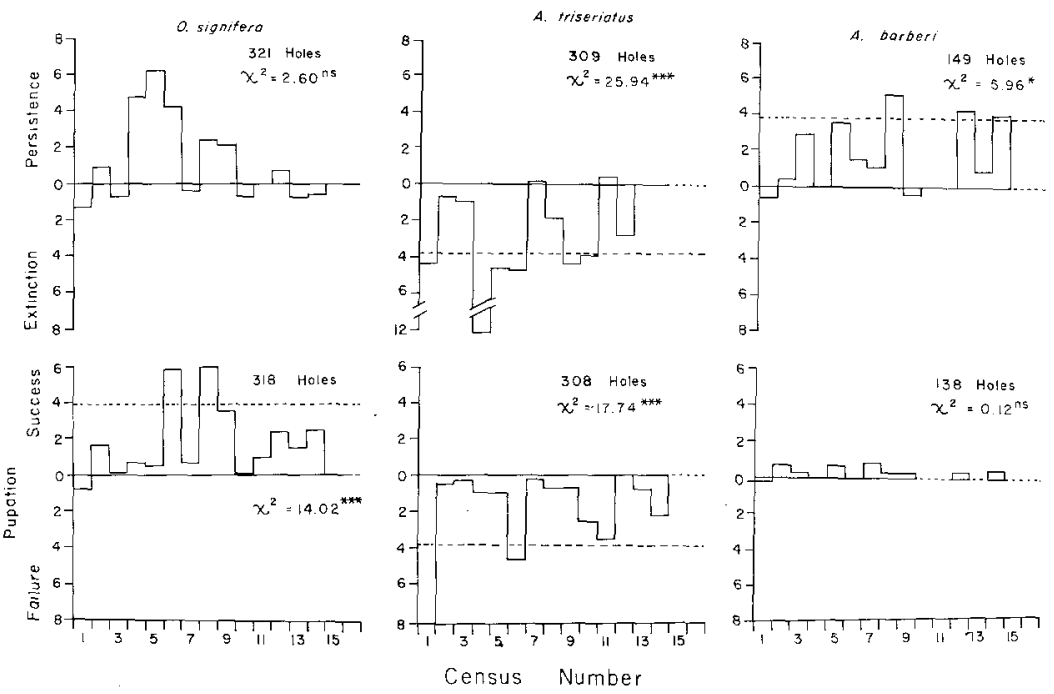

Fig. 14. Effect of the presence of T. rutilus on $O$. signifera, $A$. triseriatus, and $A$. barberi. The vertical axis plots $\chi^{2}$ with 1 degree of freedom for the association between the presence of $T$. rutilus and persistence/extinction or pupation success/failure of each species during each census. The dashed line shows the cut-off value for $P=0.05$ and is indicated only when the overall effect was significant

density factors may limit pupation of $O$. signifera in the absence of predation later in the year.

There was a sufficient number of holes with $A$. barberi to examine relationships only over all 17 censuses (Fig. 13). When the presence or absence of $T$. rutilus was disregarded, pupation per mg of $A$. barberi was positively correlated with competitor density in the current census but no significant correlations persisted when the presence or absence of $T$. rutilus was fixed. The only significant correlation explained but $5 \%$ of the variation in pupation of $A$. barberi and this degree of correlation would not be significant given the sample sizes of the latter analyses. The data available for $A$. barberi thus show no significant effects of either intraspecific or predator density and the only effect of competitor density is small and positive.

Taken as a whole, these results provide no evidence that intra- or interspecific density impedes development of $A$. triseriatus or $A$. barberi at any time of year. In $O$. signifera, negative effects of competition occur but when they do, are always less than the positive effect of intraspecific density. Finally, predation can have an adverse effect on pupation in the presence of $T$. rutilus later in the year.

\section{Predator presence and prey persistence}

Toxorhynchites are renowned for the universally voracious nature of their predatory larval habits. Relative to the other dwellers in tree-holes, they are enormous (Fig. 1). In addition, on a smaller scale $C$. appendiculata also can inflict considerable mortality within the confines of tree holes (Lounibos, 1982). We therefore now turn attention to the role of predation in the organization of this tree-hole mosquito community. Because of its size (Fig. 1), abundance, and constancy of occurrence (Fig. 4), we shall first consider the role of $T$. rutilus. On one level, we asked whether the presence of the predator in natural tree holes was associated with the persistence/extinction of each species or its ability to pupate. On another level, we examined the effects on species composition and pupation success of totally excluding $T$. rutilus from artifical tree holes (tires).

\section{Predation in natural tree holes}

$T$. rutilus consumes abundant prey but the question remains to what extent it effects the extinction or prevents metamor- phosis of the prey species co-habiting the same holes. To answer this question, we examined the relationship between a given prey species and whether its persistence and pupation success was related to the presence or absence of $T$. rutilus in our total census data of 772 wet-holes. Operationally, we constructed $2 \times 2$ contingency tables whose cells were filled in by the following protocol:

1. To be selected, a hole must have had standing water in both the previous and current census and must have had the prey species present during the previous census.

2. Those holes with prey present in the previous census were divided into two categories according to the presence or absence of $T$. rutilus.

3. Then,

$a=$ number of holes where $T$. rutilus was present in the previous census and prey were present in the current census.

$b=$ number of holes where $T$. rutilus was present in the previous census and prey were absent in the current census.

$c=$ number of holes where $T$. rutilus was absent in the previous census and prey were present in the current census.

$d=$ number of holes where $T$. rutilus was absent in the previous census and prey were absent in the current census.

$\chi^{2}=$ chi-squared corrected for continuity

(Pielou, 1977, p. 207)

$=(a d-b c-(a+b+c+d) / 2)^{2}(a+b+c+d) /$

$(a+b)(c+d)(a+c)(b+d)$.

The type of effect, positive or negative, was determined by the sign of $(a d-b c)$. If the overall $\chi^{2}$ was significant, we then performed single degree-of-freedom comparisons for each census. By setting the criterion of significance for overall $\chi^{2}$, we tried to minimze Type I errors in our between-census comparisons. As above, we wanted to examine the temporal sequence of events in holes of known conditions despite the lack of complete independence of sequential observations. Our results thus show individual census values of $\chi^{2}$ as well as the overall values. Finally, as an indicator of pupation success, we constructed contingency tables as above but used for our criterion in the present census the presence or absence of pupae only.

Altogether (Fig. 14) $T$. rutilus had no significant effect on the persistence of $O$. signifera, but $A$. triseriatus was 


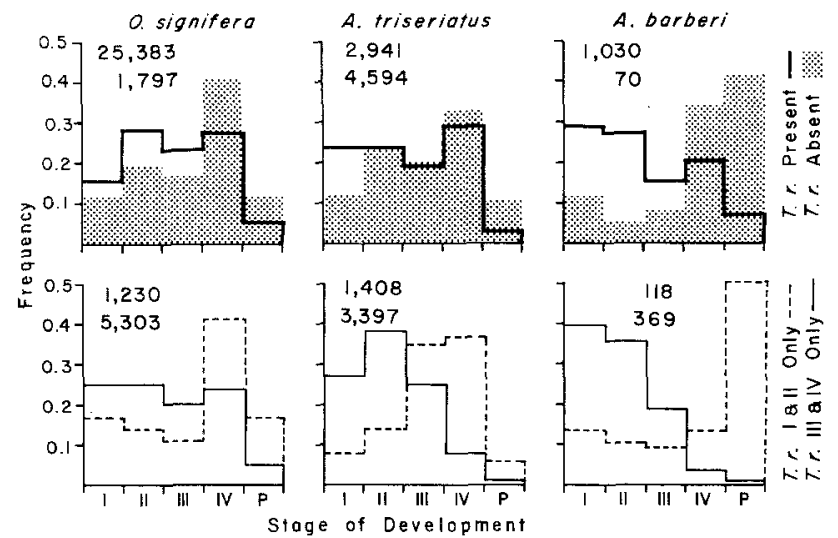

Fig. 15. Effect of $T$. rutilus on the age distribution of prey. The numbers in each graph show the number of individuals involved, the top number corresponding to the solid line, the bottom number to the dashed line or screen

more likely to go extinct and $A$. barberi to persist when $T$. rutilus was present. The presence of $T$. rutilus was associated with pupation success in $O$. signifera, pupation failure in $A$. triseriatus, and no significant effect on pupation in $A$. barberi. Thus, in holes with $T$. rutilus, $O$. signifera and $A$. barberi are more likely to persist or pupate while $A$. triseriatus is more likely to go extinct or fail to pupate.

To determine the effects of $T$. rutilus on the age structure of the prey populations, we examined the age distribution of prey in 4 subsets of the 772 wet-holes censused in 1978, those containing (1) T. rutilus in any stage, (2) only first or second instars of T. rutilus, (3) only third or fourth instars of T. rutilus, and (4) no T. rutilus. Figure 15 shows that younger prey were relatively less abundant then predators were exclusively in younger instars and that older prey were relatively less common when the predators were in older instars. Considering all holes in which T. rutilus was present regardless of age, younger instars of $O$. signifera, $A$. barberi, and A. triseriatus appeared in greater frequencies than expected from all the wet-holes where T. rutilus was absent. These results indicate first that $T$. rutilus is a size-selective predator and, second, that the net effect of $T$. rutilus predation is to selectively crop older instars and pupae of $O$. signifera, A. barberi, and A. triseriatus.

In addition to a direct effect on each species, $T$. rutilus may be influencing interspecific interactions among the prey themselves. To investigate this possibility, we constructed two sets of $2 \times 2$ contingency tables, one set consisting of holes where T. rutilus was absent in both the previous and the current census, the other set where $T$. rutilus was present in at least the previous census. Next,

1. To be selected, a hole must have had standing water in both the previous and current census and must have had the prey species being affected (species B) in it during the preceding census.

2 . These holes were then divided into two categories according to the presence or absence of species pairs, A (the impinging species) and $\mathrm{B}$ (the affected species).

3. Then,

$a=$ number of holes where species A was present during the previous census and species B persisted into the current census.

$b=$ number of wet-holes where species A was present during
Table 4. Effect of species A on species $B$ in the presence or absence of $T$. rutilus; in column $\mathrm{X},(+)$ or $(-)$ indicates a significant association of $A$ with the persistence or extinction, respectively, of species $\mathrm{B}$; in column $\mathrm{P},(+)$ or $(-)$ indicates a significant positive or negative association, respectively, of species $A$ with pupation in species B. ns indicates a non-significant association in both columns $\mathrm{X}$ and $\mathrm{P}$; NH number of wet-holes; $\chi_{c}^{2}$, chi-squared corrected for continuity

\begin{tabular}{llllrlrr}
\hline & A & B & X & $\chi_{c}^{2}$ & P & $\chi_{c}^{2}$ & NH \\
\hline T.r. & O.s. & A.t. & $(-)$ & 6.0 & ns & 0.5 & 107 \\
Absent & & A.b. & ns & 0.5 & ns & 0.9 & 13 \\
& A.t. & O.s. & ns & 0.0 & ns & 1.7 & 51 \\
& & A.b. & ns & 0.5 & ns & 0.7 & 13 \\
& A.b. & O.s. & ns & 0.3 & ns & 0.2 & 91 \\
& & A.t. & ns & 1.8 & ns & 0.8 & 144 \\
& C.a. & O.s. & ns & 3.2 & ns & 1.6 & 51 \\
& & A.t. & ns & 0.2 & ns & 0.6 & 107 \\
& & A.b. & ns & $<0.1$ & ns & 0.4 & 13 \\
T.r. & O.s. & A.t. & $(-)$ & 7.1 & ns & 0.3 & 213 \\
Present & & A.b. & $(+)$ & 8.1 & ns & 0.5 & 134 \\
& A.t. & O.s. & ns & 2.9 & $(-)$ & 10.9 & 272 \\
& & A.b. & ns & 0.1 & ns & 0.3 & 137 \\
& A.b. & O.s. & $(+)$ & 8.8 & $(+)$ & 35.9 & 231 \\
& & A.t. & $(-)$ & 12.3 & ns & $<0.1$ & 175 \\
& C.a. & O.s. & ns & $<0.1$ & ns & 0.4 & 51 \\
& & A.t. & ns & 0.2 & ns & 0.5 & 212 \\
& & A.b. & ns & 0.3 & ns & 0.2 & 135 \\
\hline
\end{tabular}

the previous census and the species B was absent in the current census.

$c=$ number of wet-holes where species A was absent during the previous census and species $\mathrm{B}$ persisted into the current census.

$d=$ number of wet-holes where species A was absent during the previous census and species $B$ was absent in the current census.

$\chi_{\mathrm{c}}^{2}$ was calculated as above except that when all row and column totals were less than 15 , we calculated probabilities directly using Fisher's exact test (Steel and Torrie, pp. 504 506).

In wet-holes without $T$. rutilus (Table 4), the presence or absence of $A$. triseriatus, $A$. barberi, or $C$. appendiculata had no significant effect on the persistence of the other species while $A$.triseriatus, but not $A$.barberi, was more likely to go extinct than expected by chance in a hole occupied by $O$. signifera. In wet-holes with $T$. rutilus, the presence of $O$. signifera and $A$. barberi increased persistence of each other and the probability of extinction of $A$. triseriatus was greater than expected by chance. By marked contrast, $A$. triseriatus had no significant effect on either $O$. signifera or $A$. barberi. Thus $O$. signifera and $A$. barberi appear to ease the effects of $T$. rutilus predation on each other but reinforce the effects of predation on $A$. triseriatus.

Interspecific effects on pupation among the prey species were significant only in the presence of $T$. rutilus, A. triseriatus having a negative and $A$. barberi a positive effect on pupation of $O$. signifera.

In either the presence or absence of T. rutilus, C. appendiculata had no significant effect on the persistence or pupation of $O$. signifera, $A$. triseriatus, or $A$. barberi. The major effect of predation in tree holes at Tall Timbers thus derives from $T$. rutilus and not $C$. appendiculata. 

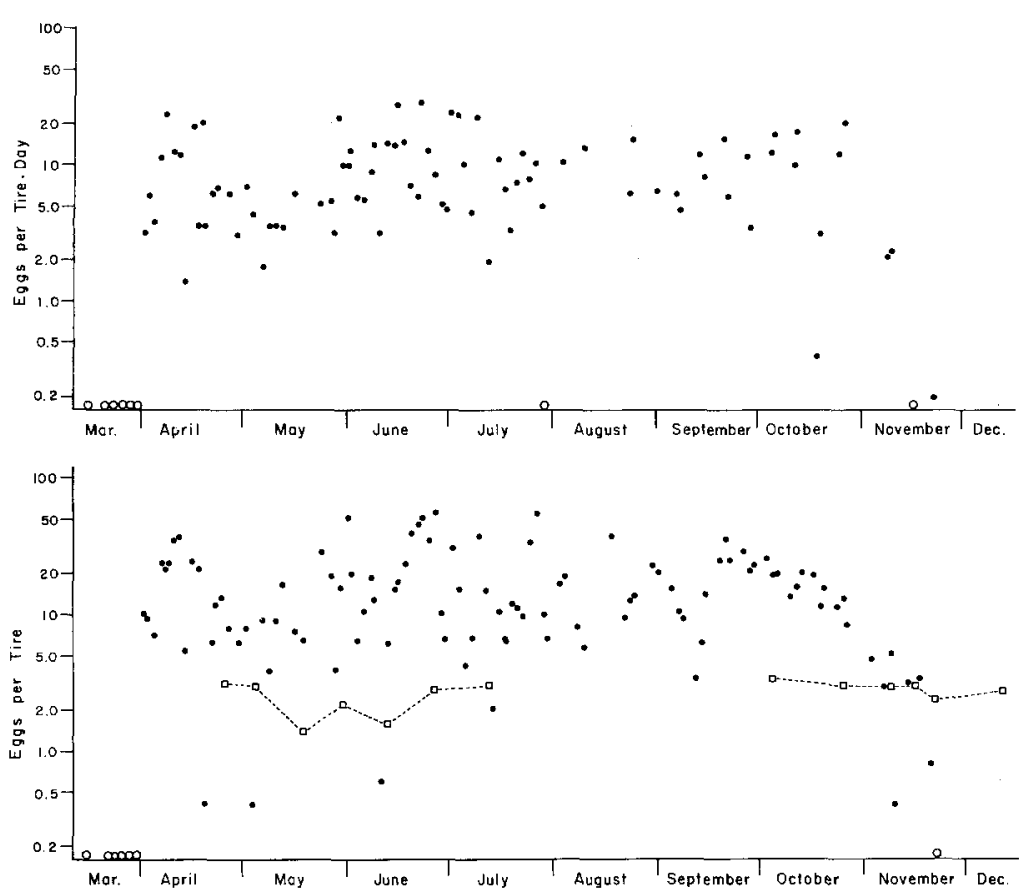

Fig. 16. Abundance of T. rutilus eggs in tires where eggs were removed at least every $72 \mathrm{~h}$ (top) or left remaining (bottom). The squares connected with a dashed line in the bottom graph indicate the mean number of $T$. rutilus larvae and pupae per tire on the date censused. The open circles indicate days when no eggs were found in those tires

\section{Predation in tires}

To examine further the effects of predation by $T$. rutilus, we sought to control their access to a habitat and have an accurate assessment of prey output. For this purpose, we hung 10 tires in Woodyard Hammock (Fig. 2). From March to December, 1978, we examined these tires at least every $72 \mathrm{~h}$ during which time we collected the pupal exuviae of any mosquitoes having ecdysed, checked the water top to bottom for the presence of $T$. rutilus, and removed all egg rafts of non-tree-hole mosquitoes, presumably $C$. restuans. From 5 of the tires, we counted and removed all eggs of $T$. rutilus and any larvae of $T$. rutilus; from 5 other tires, we counted but did not remove the eggs or larvae of $T$. rutilus. Since we used a flashlight to check the entire water column, we should have censused $100 \%$ of the larval and pupal population as well as any pupal exuviae which may have become submerged. We censused and replaced the contents of tires about every 2 weeks during April-July and October-December. Otherwise, the natural flux of mosquitoes into and out of the tires was not inhibited in any way.

Figure 16 shows the number of eggs observed in both sets of tires and the number of $T$. rutilus found in the tires in which we allowed them to colonize freely. $T$. rutilus eggs first appeared early in April and the tires received a steady influx from April through October. The number of eggs in tires declined during November and we observed no new eggs oviposited in December. Pooling the data for all five tires in a set at each census, we removed a geometric mean of $4.66 T$. rutilus eggs per tire per day (excluding the census in late July when none of the tires contained any eggs); from the set of tires in which we left the eggs, we observed a geometric mean of 9.72 eggs per tire per census. Because we counted eggs every 1-3 days, the latter set of tires certainly contained eggs counted twice and the average flux of eggs into tires is best estimated by the former mean. From our bi-weekly censuses, we estimated a standing crop of 5.2 pre-adult $T$. rutilus per tire of which $28 \%$ were first
Table 5. Effect of the presence or absence of T. rutilus on the number of adult prey ecdysing from tires between March and December, 1978. The value of $\chi^{2}$ with 1 degree of freedom was generated assuming the same proportion of $A$. triseriatus and $O$. signifera $+A$. barberi would ecdyse from either set of tires

\begin{tabular}{lccl}
\hline & \multicolumn{2}{c}{ T. rutilus } & \\
\cline { 2 - 4 } & Present & Absent & $\chi^{2}$ \\
\hline A. triseriatus & 0 & 213 & 23.9 \\
O. signifera & 43 & 151 & 28.2 \\
A. barberi & 1 & 29 & \\
\hline
\end{tabular}

instars, 13 seconds, $11 \%$ thirds, $43 \%$ fourths, and $5 \%$ pupae. From these 5 tires, we recorded a total of 15 pupal exuviae for an average of 3.0 T. rutilus emerging per tire during the year. Thus, over the same period at an oviposition rate of 4.66 eggs per tire per day, one adult ecdysed for every 208 eggs deposited.

From these same two sets of tires, we recovered 437 pupal exuviae of other mosquito species. Of these, 44 emerged from tires with $T$. rutilus and 393 from tires without $T$. rutilus (Table 5). When $T$. rutilus were absent, more $A$. triseriatus than $O$. signifera $+A$. barberi emerged; in the presence of $T$. rutilus a few $O$. signifera $+A$. barberi continued to emerge but no $A$. triseriatus exuviae were ever found in any of these latter tires. Thus, in addition to an $89 \%$ reduction in prey emergence, $T$. rutilus in tires effected a shift in emergence success from $A$.triseriatus to. $O$. signifera + A. barberi.

\section{Cannibalism in T. rutilus}

Both our own observations in the laboratory and field and the observations of others (Steffan and Evenhuis 1981) show that $T$. rutilus kill not only other species of prey, but also each other. One cannot examine the effect of T. rutilus' predation on itself in the same manner as we did above 
Table 6. A Proportion of total development time of $T$. rutilus spent in each stage at $19^{\circ}$ or $27^{\circ} \mathrm{C}$ (spanning the temperature prevailing in tree holes at Tall Timbers May to October, 1978); calculated from Trimble and Smith (1979). B Observed and expected frequencies of each stage of $T$. rutilus found in 340 wet-holes during censuses 5-17; expected number $=$ (relative duration of the stage from (A)) times total number of all stages)

A. $\%$ total development time $(\mathrm{L}: \mathrm{D}=15: 9)$ first instar to adult

\begin{tabular}{lll}
\hline & $19^{\circ} \mathrm{C}$ & $27^{\circ} \mathrm{C}$ \\
\hline I & 11 & 10 \\
II & 12 & 13 \\
III & 15 & 15 \\
IV & 34 & 34 \\
P & 28 & 28 \\
\hline
\end{tabular}

B. Observed and expected numbers in each age class

\begin{tabular}{lrrrrr} 
& I & II & III & IV & P \\
\hline Observed & 238 & 136 & 184 & 485 & 91 \\
Expected & 117 & 145 & 175 & 386 & 313 \\
$\chi^{2}$ & 125 & $<1$ & $<1$ & 25 & 157 \\
Observed & 238 & 136 & 184 & 485 & - \\
Expected & 146 & 187 & 219 & 490 & - \\
$\chi^{2}$ & 58 & 14 & 6 & $<1$ & \\
Observed & - & 136 & 184 & 485 & - \\
Expected & - & 159 & 197 & 449 & - \\
$\chi^{2}$ & & 3.3 & 0.9 & 2.9 & \\
\hline
\end{tabular}

for other prey; rather, assuming no other source of mortality, we estimated the impact of cannibalism first by comparing expected instar ratios from developmental rates and second by pupae: egg ratios.

Trimble and Smith (1979) provide data on the duration of pre-adult development in T. rutilus from southern Louisiana. While temperature has a profound effect on the total duration of pre-adult development, the ratio of the duration of a given instar to the total remains surprisingly constant at $19^{\circ}$ and $27^{\circ} \mathrm{C}$ (Table 6A). Assuming no larval or pupal mortality and a stationary age distribution, relative abundances of each stage of development should correspond to their relative durations. If cumulative mortality increased with developmental age, then there should be a progressive departure from these frequencies, i.e., younger instars should be uniformly more abundant and older instars uniformly less abundant than expected. To avoid the effects of photoperiod which may modify the rates of larval development or induce diapause in later instars (Bradshaw and Holzapfel 1975; Holzapfel and Bradshaw 1977; Trimble and Smith 1979) and thus bias our assumptions, we examined the instar distribution and egg abundances from late April (census 5) through mid-October (census 17) while oviposition (Fig. 16) and pupation (Fig. 12) were still taking place. The observed total numbers of each stage from the 35 holes we sampled during this period are shown in Table 6B. In these holes, we found an excess of first and fourth instars and a deficiency of pupae. Since the latter could result either from the effects of predation on pupae or by food(prey)-limited growth in the fourth instar (Breland 1949; Jenkins and Carpenter 1946), we also examined the distribution of the four larval instars alone (Table 6B). In the latter case, there was again an excess of first instars but a deficiency of seconds and thirds. Final-

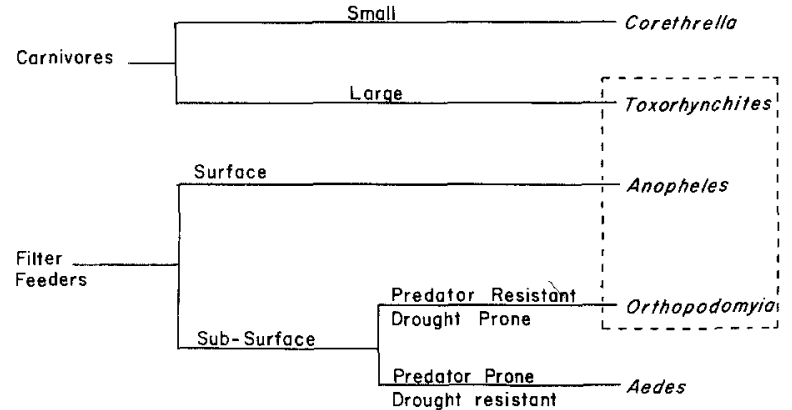

Fig. 17. Habitat segregation of tree-hole mosquitoes at Tall Timbers. The dashed line encloses the species normally associated with one another in the more permanent holes

ly, it is possible that first instars are cannibalistic, inter se. Examining the distribution of second, third, and fourth instars alone (Table 6B), there are still more fourths and fewer seconds and thirds than expected from chance. These data support the hypothesis that $T$, rutilus is cannibalistic and indicate that in natural tree holes fourth instars are consuming younger instars, especially seconds and thirds.

\section{Discussion}

\section{Organization of the mosquito community (Fig. 17)}

The negative association (Fig. 10; Table 3), the low level of interspecific encounter (Fig. 11), and high level of intraspecific encounter (Fig. 11) indicate that $A$. triseriatus live in a sub-habitat which is distinct from that occupied by $T$.rutilus, $O$. signifera, and $A$.barberi. A.triseriatus possess drought-resistant eggs; they predominate in smaller (Fig. 5), more drought-prone (Fig. 6) holes and they are able to invade rapidly dry holes after either a short (Fig. 7) or long (Fig. 8) dry period. A. triseriatus alone occupy holes without regard to their permanency; $T$. rutilus, $O$. signifera, and $A$. barberi are positively associated (Fig. 10, Table 3) in the larger (Fig. 5), more permanent holes (Fig. 6). Hence, the permanence of the aquatic medium is a major factor organizing tree-hole mosquito communities.

Trophic specialization is also an important factor organizing the mosquito community. Both T. rutilus and C.appendiculata are carnivorous, readily attacking the filterfeeding prey, each other, and, at least in the case of T. rutilus, themselves. C. appendiculata is the smallest member of the community (Fig. 1) and feeds mainly on the smaller, younger instars of prey (Petersen and Chapman, 1969; Lounibos, personal communication). C. appendiculata appears to share characteristics with both the $A$. triseriatus and T. rutilus-O. signifera-A. barberi subcommunities (Fig. 10; Table 3). C. appendiculata persisted through a long-term drought (Fig. 8) but was slow to invade previously dry holes after a short-term drought (Fig. 7). In terms of biotic interactions, the presence or absence of C. appendiculata had no effect on the persistence or pupation of any filter-feeding prey, regardless of the presence or absence of $T$. rutilus (Table 4). Finally, excluding C. restuans and $C$. melanura which are normally considered groundwater mosquitoes (Horsfall 1955), C. appendiculata was the least prevalent tree-hole species at Tall Timbers (Fig. 4). This pattern varies substantially from that observed in peninsular Florida where $C$. appendiculata is the 
major predator and second in its abundance only to $A$. triseriatus (Lounibos 1982). These observations suggest that, although regularly encountered at Tall Timbers, C. appendiculata at this latitude has little impact on the tree-hole community as a whole.

By marked contrast, $T$. rutilus can have a tremendous impact on prey populations; $T$. rutilus is the largest member of the community (Fig. 1) and affects mainly the older prey instars (Fig. 15). Their presence in our study tires reduced prey emergence by $89 \%$ (Table 4 ). The steady appearance of $T$. rutilus eggs in these tires from April through November (Fig. 16) illustrates their potential to invade new holes, even during a prolonged drought. Indeed, after $A$. triseriatus, $T$. rutilus was the most rapid colonist of formerly wet holes (Fig. 7).

In addition to the reduction of prey in tires, the presence of $T$.rutilus reversed the dominance in emergent species from A. triseriatus to O. signifera $+A$. barberi (Table 5). Similarly, in actual tree holes, $T$. rutilus significantly increased the probability that $A$. triseriatus would to extinct (Fig. 14) and decreased pupation success (Figs. 13, 14) in this same species. Under these same conditions, $O$. signifera and $A$. barberi were able to persist, pupate, and emerge (Fig. 14; Table 5).

While we have no direct evidence to explain differential predator susceptibility, we can propose several explanations for why $O$. signifera and $A$. barberi may be more resistant than $A$. triseriatus. (1) $O$. signifera possess longer, stouter bristles emerging from their thoracic and abdominal lateral tufts (Fig. 1) than those found on A. triseriatus. These bristles may decrease the strike-capture success ratio of $T$. rutilus attacking $O$. signifera. (2) A. barberi, like other anophelines (Clements 1963, pp. 33-36; Bates 1949, pp. 132-135), are highly specialized surface feeders. Larvae of $A$. barberi lie motionless immediately below the surface, using their mouth brushes to create wide vortices which bring food particles floating on the surface film to their mouths. $O$. signifer $a$ and $A$. triseriatus feed while swimming along the edge or bottom of the hole or while hanging from the surface tension and cruising through the upper layer of the water column. Since motion is an important proximal orientation cue to Toxorhynchites (Paine 1934; Goma 1964; Rubio et al. 1980), A. barberi may experience an attack rate much lower than $O$. signifera or $A$. triseriatus. (3) Table 4 shows that one of the few significant interactions among the prey species is that between $O$. signifera and $A$. barberi where both persistence and pupation of $A$. barberi in the presence (but not absence) of $T$. rutilus is enhanced by the additional presence of $O$. signifera. Crans and Slaff (1977) report that among T.rutilus in New Jersey, subsurface predation is more common than surface predation but Spielman (A. Spielman, personal communication) observed that in southern tupelo gum holes where $A$. barberi is the predominant filter feeder, T. rutilus lurk and feed mainly on the surface. It would thus appear that $T$. rutilus may adjust their behavior to coincide with the more abundant prey. Such behavior is not without precedent as the species-selective behavior of $T$. theobaldi in the laboratory depends upon the prey species it has encountered earlier in its development (Rubio et al. 1980). Switching behavior by $T$. rutilus and the spatial separation of $A$. barberi and $O$. signifera in tree holes may account for the mutual, beneficial effect that these species derive from one another in tree holes with T. rutilus (Table 4).
By virtue of their size and selective predation, T. rutilus and C. appendiculata mainly exploit separate age classes of prey. Similarly, due to differences in drought and predator tolerance as well as trophic specialization, the non-predatory species exploit distinct types of tree holes or zones within holes. The five species of tree-hole dwelling mosquitoes at Tall Timbers thus appear to effectively partition their finite habitat (Fig. 17).

\section{The ghost of competition past}

Despite the circumscribed nature of their habitat, there is little evidence that tree-hole mosquitoes at Tall Timbers are at equilibrium or compete for limiting resources. $A$. triseriatus predominate in perhaps the most distinct subhabitat, the smaller transient hole. They experience the highest level of intraspecific and total crowding by filter feeders (Fig. 11). Pupation takes place mainly during the spring and early summer (Fig. 12) and population biomass declines during the year (Fig. 4). While this pattern suggests intraspecific crowding factors to be important to $A$. triseriatus, pupation success per mg standing crop of $A$. triseriatus is positively correlated with intraspecific density (Fig. 13). $T$. rutilus negatively affects both survival and pupation of A. triseriatus (Fig. 14). Predation by T.rutilus may be especially important later in the summer when continued rains (Fig. 3) have permitted its high penetrance into most of the tree holes (Fig. 7) and pupation success of A. triseriatus is negatively affected by predator density (Fig. 13). The only negative interspecific effect on $A$. triseriatus is reduced pupation success associated with the presence of $O$. signifera but only in the additional presence of T. rutilus (Table 5). When $T$. rutilus is absent, there is no significant effect of $O$. signifera on either persistence or pupation of $A$. triseriatus, indicating that the negative effect of $O$. signifera on $A$. triseriatus is somehow related to predation, not interspecific crowding. Thus, it would appear that predation maintains population levels of $A$. triseriatus below those where intra- or interspecific competition is an important factor.

After A.triseriatus, A. barberi exhibit the highest level of total crowding among filter feeders (Fig. 11), but intraspecific density has no significant impact and interspecific "competitor" density has a small positive effect on pupation success of $A$. barberi (Fig. 13). In addition, A. barberi is a facultative carnivore (Petersen et al. 1969) and if not provided with other prey, readily turns cannibalistic in the laboratory. A. barberi, like $T$. rutilus, may thus be partially self-limiting by cannibalism when resources decline. In sum, there is no evidence that limiting resources result in either intra- or interspecific competition for $A$. barberi. On the contrary, like $A$.triseriatus, predation may be responsible for keeping $A$. barberi at low population levels (Fig. 4) and low levels of intraspecific crowding (Fig. 11).

While experiencing less total crowding from filter feeders, $O$. signifera exhibit a higher level of intraspecific crowding than A.barberi (Fig. 11). Intraspecific competition is unlikely, however, since pupation persists all summer long and, as in A. triseriatus, is generally positively correlated with intraspecific density (Fig. 13). In the absence of T. rutilus and later in the year, other filter feeders do have a negative effect on pupation success (Fig. 13) and they may expalin why, despite maintaining the same biomass throughout the year (Fig. 4), pupal production is lower in the late summer than in the spring (Fig. 12). In the absence 
of $T$. rutilus further north, A. triseriatus is the predominating species and both $O$. signifera and $A$. barberi exist at low frequencies until later in the year when the larval population of A. triseriatus declines (Mitchell and Rockett 1981) as the latter enter diapause as embryos (Shroyer, 1979). At Tall Timbers, $O$. signifera coexist with $T$. rutilus in the larger, more permanent holes; in tires $T$.rutilus greatly reduce adult ecdysis of $O$. signifera (Table 5) and the effects of $T$. rutilus on the age distribution of $O$. signifera in tree holes (Fig. 15) suggests that they also consume large numbers of the latter under natural conditions. Thus, although $O$. signifera may experience some competitive pressure from other filter feeders, these effects are restricted to the mid- and late summer and do not prevent $O$. signifera from producing pupae in greater abundance than any other species.

We can say less about competition between $T$. rutilus and $C$. appendiculata. The data in Table 6 suggest that $T$. rutilus regulate their own numbers through cannibalism and while cannibalism can be viewed as an ultimate form of interference competition, it is not necessarily competition for a limiting resource. Despite a persistently high standing crop of T. rutilus (Fig. 4), pupation declines during the year (Fig. 12). At the same time, levels of $O$. signifera, remain high (Fig. 4) and the decline in pupation from censuses 5-9 (Fig. 12) occurs at a time of year when C. appendiculata is at its lowest level (Fig. 4). Although we do not know to what extent $C$. appendiculata is cannibalistic, larvae exhibit a higher level of intraspecific crowding than T. rutilus but also a higher density and greater diversity of potential prey, including both $A$. triseriatus and $O$. signifera (Fig. 11). Finally, C. appendiculata, both by virtue of its seasonal abundance (Fig. 4) and pupation (Fig. 12) was bivoltine at Tall Timbers in 1978 and appeared to realize its greatest pupation success later in the season. In sum, while we cannot exclude intraspecific competition among $T$. rutilus, there is certainly little evidence to support such a concept and even less to confirm trophic resource limitations in C. appendiculata.

The picture which emerges is one of a community whose constituent species are held below their carrying capacities by a self-limiting cannibalistic predator. This conclusion does not mean that competition is never important in any hole at any time; rather, viewed on the scale of the broader community, it does not appear to be of any consequence. On a local, within tree-hole basis, extinctions and reinvasions are common, amounting to at least one species for every 2 holes every two weeks (Table 1 ). Moreover, even though there may be selection by ovipositing females for certain types of tree holes, in the system as a whole, extinctions and immigrations occur without regard to community composition, tree-hole size or stability, or average number of species present (Tables 1-2). In these respects, tree-hole mosquito communities at Tall Timbers closely resemble the simulated dynamics of predator mediated, non-equilibrium coexistence by Caswell (1978). Much as Caswell's local predator affects the relative distribution but not the extinctionpersistence of the prey, $T$. rutilus affects the relative abundances of $O$. signifera, A. triseriatus and A. barberi at Tall Timbers; on a geographic scale, all three species persist in its presence from about $30-40^{\circ} \mathrm{N}$ latitude and despite its absence further north in the upper midwest (Mitchell and Rockett 1981; Jenkins and Carpenter 1946).

The circumscribed habitat of tree holes initially sug- gested that competition for limiting resources ought to be an important factor organizing this community. It is becoming increasingly recognized that competition regulates the number of species in a community only when the numbers of that community actually compete; i.e., when they are at or near their carrying capacity (Menge and Sutherland 1976). Despite the apparent limitation of finite habitats such as grass stems (Rathcke 1976), the edges of unrolling tropical leaves (Strong 1981), or the basal tree holes in the current study, insect populations of similar species may coexist well below their carrying capacities and not competitively exclude one another. Perhaps it is time to exorcise the "ghost of competition past" (Connell 1980), resurrecting it not for a convenient explanation, but only when coevolved niche shifts or competitive exclusion can be clearly demonstrated.

\section{Origins of habitat partitioning}

If competitive interactions have played little role in the establishment of sub-habitat differences of basal tree-hole mosquitoes in north Florida, the question then remains as to the origin of these differences. The two genera, Orthopodomyia and Toxorhynchites, are typically, if not exclusively, container breeders throughout their world-wide range ( $\mathrm{Za}$ vortink 1968; Steffan and Evenhuis 1981) and O. signifera is thought to be more derived than its tree-hole breeding congeners (Zavortink 1968, 1970). Corethrella are frequent container-breeders in both the New World tropics (Lane 1942) and Southeast Asia (Beaver 1979, 1982). Anopheles barberi is but one of some 6 New World tree-hole anophelines and perhaps the most recently evolved of the group (Zavortink 1970). The subgenus Protomacleaya, to which A. triseriatus belongs, "with more than 40 species, is the dominant subgenus of tree-hole breeding Aedes in the New World" (Zavortink 1972). Tree-hole breeding members of the genera Toxorhynchites, Orthopodomyia, Aedes and Anopheles coexist sympatrically in Asia (Chow 1949; Lu 1980; Tanaka et al. 1979) and in temperate Europe Anopheles, Aedes, and Orthopodomyia may occupy the same holes (Tate 1932; Kitching 1971; Mattingly 1969). It is thus clear that $T$.rutilus, O. signifera, A.triseriatus, A. barberi and $C$. appendiculata belong to genera or subgenera whose constituent species frequently or exclusively occupy tree holes in tropical to north-temperate zones. There is, therefore, no reason to suppose that coexistence in temperate North American tree holes by these species is a consequence of co-evolved niche shifts; rather, the principal determinants of their coexistence probably relate to the adaptations already possessed by each species at the time of their first encounter.

In addition to the species we found in tree holes at Tall Timbers, Aedes hendersoni and Orthopodomyia alba, which are closely related to, if not sibling species of, $A$. triseriatus and $O$. signifera, are common elsewhere in North America. We believe that if competitive exclusion or coevolved niche shifts can be demonstrated in temperate North American tree-hole mosquitoes, it will be between one of these species pairs.

The foregoing discussion indicates effective habitat separation among tree-hole mosquitoes in eastern North America and further suggests that this separation followed from adaptations already possessed at the time of colonization. If few co-evolutionary niche-shifts have taken place, 
the community remains below the carrying capacity for most or all species, and competition plays little or no role in determining community structure, are there then subhabitats available for the colonization of new species? The answer to this question is almost certainly affirmative.

Superficially, it might appear that the tree holes at Tall Timbers already included two different size-selective predators as well as filter feeders which separate according to the height of the forest (A.hendersoni, A.triseriatus), drought resistance (A. triseriatus, $O$. signifera), and withinhole spatial feeding patterns $(A$. barberi, $O$. signifera $)$. However, other localities contain many more species. Lu (1980) lists 32 species of mosquitoes found in tree holes of mountain forests on Hainan Island. Lounibos (1981) made a careful, quantitative study of 22 sympatric species of tree-hole mosquitoes on the Kenya coast. He found habitat segregation similar to the ones described in the present study but, in addition, found separation by macro-habitat such as peridomestic, river bed, cultivated, and ecotonal areas and by subtle differences in hatching pattern. In addition, those species of Aedes which overlapped to the greatest extent in macro- and microhabitat exhibited strikingly different hatching patterns: the greatest majority of the eggs of one species hatched upon the first flooding of a tree hole, the eggs of the other species hatching little by little in successive floodings, thereby separating the two species in time. This degree of habitat segregation has not been approached at Tall Timbers and the number of available subhabitats is more likely limited by human ability to perceive them than mosquito ability to exploit them.

From the point of view of co-evolution, one might conclude that the greater the number of species in a community, the greater the subtlety in their niche separations. This statement reflects reasoning adherent to theories of limiting similarity and species packing. Equally plausible is the concept that multiple opportunities present themselves and when appropriately adapted species encounter these opportunities, they are exploited. Mattingly (1969) states that "It is nearly true to say that if it holds water mosquitoes will breed in it somewhere or other." The tree holes at Tall Timbers are bounded by the Atlantic Ocean to the east, the Gulf of Mexico to the south, the arid region of the southwest, and harsh winters to the north. Lounibos' (1981) tree holes on the Kenyan coast lie in the tropical forest belt across equatorial Africa. Not only is there a great diversity of forest macrohabitats as described by Lounibos (1981) but also a variety of other container microhabitats such as fruit husks, snail shells, and plant axils, all containing water and each with its own particular mosquito fauna (Lounibos 1978, 1979, 1980; Lounibos and Munstermann 1981). It should be no surprise, given a rich mosquito fauna with a great variety of exploitative abilities evolved in unique or highly divergent habitat types, that this same fauna could incidentally possess more subtle mechanisms to partition tree holes. Again, we do not mean to imply that coevolution never takes place in tree holes. Rather, we reiterate that competition and coevolved niche shifts, unless experimentally demonstrated or reasonably inferred from circumstantial evidence, cannot be invoked to explain the coexistence of a diversity of species within a habitat type, no matter how circumscribed or discrete that habitat.

Acknowledgements. Much of the background work leading up to the year we spent at Tall Timbers was completed with help and encouragement from Donald Strong, D. Bruce Means, E.V. Komarek, Frances James, Donald Kaufman, Pilar Bradshaw, and Philip Lounibos. Forest Kellog, Gary Doster, Leslie Thrasher, Mel Burns, Louis Beckham, Greg Stewart, Pilar Bradshaw, Philip Lounibos, and Virginia Vail reported many findings of tree holes. We thank Lee Szyska for long hours of assistance in the field and Gregory Daly for his help in data analysis. We have profited from many long discussions with Bruce Means, Peter Frank, and, especially, Philip Lounibos. Finally, we are very grateful to Philip Lounibos and Philip Corbet for prompt, careful reviews of our preliminary manuscript and to the Tall Timbers Research Station and the National Science Foundation (DEB74-00918; DEB7822799) for support of this project.

\section{References}

Abrams P (1975) Limiting similarity and the form of the competition coefficient. Theor Pop Biol 8:356-375

Bates M (1974) The natural history of mosquitoes. New York: MacMillan

Beaver RA (1979) Biological studies of the fauna of pitcher plants (Nepenthes) in west Malaysia. Ann Soc Entomol Fr 15:3-17

Beaver RA (1982) The community living in Nepenthes pitcher plants: Fauna and food webs. In:Frank JH, Lounibos LP (eds) Terrestrial plants as hosts of aquatic insect communities, Marlton Plexus, pp 129-159

Bradshaw WE, Holzapfel CM (1975) Biology of tree-hole mosquitoes: Photoperiodic control of development in northern Toxorhynchites rutilus (Coq.). Can J Zool 53:713-719

Breland OP (1949) The biology and the immature stages of the mosquito, Megarhinus septentrionalis Dyar \& Knab. Ann Entomol Soc Amer 42:38-47

Brown JH, Reichman OJ, Davidson DW (1979) An experimental study of competition between seed-eating desert rodents and ants. Amer Zool 19:1129-1143

Caswell H (1978) Predator-mediated coexistence: A nonequilibrium model. Amer Natur 112:127-154

Chow CY (1949) Observations on mosquitoes breeding in plant containers in Yunnan. Ann Entomol Soc Amer 42:465 470

Clements AN (1963) The physiology of mosquitoes. Oxford: Pergamon Press, Ltd.

Cody ML (1966) A general theory of clutch size. Evolution $20: 174-184$

Cody ML (1974) Competition and the structure of bird communities. Princeton: Princeton University Press

Connell JH (1961) The influence of interspecific competition and other factors on the distribution of the barnacle Cthamalus stellatus. Ecology 42:710-723

Connell JH (1980) Diversity and the coevolution of competitors, or the ghost of competition past. Oikos 35:131-138

Corbet PS (1964) Observations on mosquitoes ovipositing in small containers in Zika forest, Uganda. J Anim Ecol 33:141-164

Crans WJ, Slaff ME (1977) Growth and behavior of colonized Toxorhynchites rutilus septentrionalis. Mosq News 37:207-211

Dayton PK (1975) Experimental evaluation of ecological dominance in a rocky intertidal algal community. Ecol Monogr 45:137-159

Diamond JM (1978) Niche shift and the rediscovery of interspecific competition. Amer Sci 66:322-331

Fish D, Carpenter SR (1982) Leaf litter and larval mosquito dynamics in tree-hole ecosystems. Ecology $63: 283-288$

Gilpin ME, McClelland GAH (1979) Systems analysis of the yellow fever mosquito Aedes aegypti. Fortschr Zool 25:355-388

Goma LH (1964) Laboratory observations on the influence of illumination on the predatory habits of Toxorhynchites larvae (Diptera, Culicidae). Ann Trop Med Parisitol 58:350-354

Grant PR (1972) Interspecific competition among rodents. Ann Rev Ecol Syst 3:79-105

Grimstad PR, Garry CE, DeFoliart GR (1974) Aedes hendersoni and Aedes triseriatus (Diptera: Culicidae) in Wisconsin: Char- 
acterization of larvae, larval hybrids, and comparison of adult and hybrid mesoscutal patterns. Ann Entomol Soc Amer 67:795-804

Holzapfel CM, Bradshaw WE (1976) Rearing of Toxorhynchites rutilus septentrionalis (Diptera: Culicidae) from Florida and Pennsylvania with notes on their pre-diapause and pupal development. Ann Entomol Soc Amer 69:1062-1064

Holzapfel CM, Bradshaw WE (1981) Geography of larval dormancy in the treehole mosquito, Aedes triseriatus (Say). Can J Zool 59:1014-1021

Horsfall WR (1955) Mosquitoes. Their bionomics and relation to disease. New York: The Ronald Press Co

Howard LO, Dyar HG, Knab F (1913) The mosquitoes of North and Central America and the West Indies. Washington: Carnegie Institution of Washington

Hurlbert SH (1978) The measurement of niche overlap and some relatives. Ecology 59:67-77

Hutchinson GE (1959) Homage to Santa Rosalia, or why are there so many kinds of animals? Amer Natur 93:145-159

Istock CA, Wasserman SS, Zimmer H (1975) Ecology and evolution of the pitcher-plant mosquito: 1. Population dynamics and laboratory responses to food and population density. Evolution $29: 296-312$

Jenkins DW, Carpenter SJ (1946) Ecology of the tree hole breeding mosquitoes of nearctic North America. Ecol Monogr 16:33-47

Keilin D (1932) On the water resevoir of a horse-chestnut tree. Parasitol 24:280-282

Kitching RL (1971) An ecological study of water-filled treeholes and their position in the woodland ecosystem. J Anim Ecol $40: 281-302$

Kitching RL (1982) Community structure in water-filled treeholes in Europe and Australia - Comparisons and speculations. In: Frank JH, Lounibos LP (eds) Phytotelmata: Terrestrial plants as hosts of aquatic insect communities. Marlton: Plexus, pp 205-222

Lane J (1942) Dixinae e Chaoborinae. Revisão das espécies neotrópicas (Diptera, Culicidae). Rev Entomol 13:81-148

Lloyd M (1967) 'Mean crowding'. J Animal Ecol 36:1-30

Lounibos LP (1978) Mosquito breeding and oviposition stimulant in fruit husks. Ecol Entomol 3:299-304

Lounibos LP (1979) Mosquitoes occurring in the axis of Pandanus rabaiensis Rendle on the Kenya coast. Cah ORSTOM, sér Ent méd Parasitol 17:25-29

Lounibos LP (1980) The bionomics of three sympatric Eretmapodites (Diptera: Culicidae) at the Kenya coast. Bull Entomol Res 70:309-320

Lounibos LP (1981) Habitat segregation among African treehole mosquitoes. Ecol Entomol 6:129-154

Lounibos LP (1983) The mosquito community of treeholes in subtropical Florida. In: Frank JH, Lounibos LP (eds) Terrestrial plants as hosts of aquatic insect communites. Marlton: Plexus, pp 223-246

Lounibos LP, Munstermann LE (1981) Ecological and genetic separation of three sympatric species of Aedes (Diptera: Culicidae) rom the Kenya coast. Bull Entomol Res 71:639-648

Lu PL, Li BS, Xu RM, Jiang YY (1980) The composition of treehole breeding mosquitoes in the mountain forests of Diaolou, Hainan İsland (Diptera: Culicidae). Bull Acad Military Med Sci (Peking) 1980(1):55-59

Lubchenco J, Menge BA (1978) Community development and persistence in a low rocky intertidal zone. Ecol Monogr 48:67-94

MacArthur RH (1972) Geographical Ecology, New York: Harper and Row

MacArthur RH, Levins R (1967) The limiting similarity, convergence, and divergence of coexisting species. Amer Natur 101:377-385

Mattingly PF (1969) The biology of mosquito-borne disease. London: Allen and Unwin

Menge BA, Sutherland JP (1976) Species diversity gradients: synthesis of the roles of predation, competition, and temporal heterogeneity. Amer Natur 110:351-369
Mitchell L, Rockett CL (1981) An investigation on the larval habitat of five species of tree-hole breeding mosquitoes (Diptera: Culicidae). Great Lakes Entomol 14:123-129

Moeur JE, Istock CI (1980) Ecology and evolution of the pitcherplant mosquito IV. Larval influence over adult reproductive performance and longevity. J Animal Ecol 49:775-792

Moore CG, Fisher BR (1969) Competition in mosquitoes. Density and species ratio effects on growth, mortality, fecundity, and production of growth retardant. Ann Entomol Soc Amer 62:1325-1331

Nie NH, Hull CH, Jenkins JG, Steinbrenner K, Bent DH (1975) SPSS: Statistical package for the social sciences. New York: McGraw-Hill

Paine RT (1974) Intertidal community structure. Oecologia (Berlin) $15: 93-120$

Paine RW (1934) The introduction of Megarhinus mosquitoes into Fiji. Bull Entomol Res 25:1-32

Petersen JJ, Chapman HC (1969) Chemical factors of water in tree holes and related breeding of mosquitoes. Mosq News $29: 29-36$

Petersen JJ, Chapman JC, Willis OR (1969) Predation of Anopheles barberi Coquillett on first instar mosquito larvae. Mosq News $29: 134-135$

Pianka ER (1969) Sympatry of desert lizards (Ctenotus) in Western Australia. Ecology 50:1012-1030

Pielou EC (1977) Mathematical Ecology. New York: John Wiley

Pittendrigh CS (1950) The ecotopic specialization of Anopheles homunculus; and its relation to competition with $A$. bellator. Evolution $4: 64-78$

Rathcke BJ (1976) Competiton and coexistence within a guild of herbivorous insects. Ecology 57:76-87

Rubio Y, Rodriguez D, Machado-Allison EE, León JA (1980) Algunos aspectos el comportamiento de Toxorhynchites theobaldi (Diptera Culicidae). Acta Cient Venezolana 31:345-351

Schoener TW (1974) Resource partitioning in ecological communities. Science 185:27-39

Scholl PJ, DeFoliart GR (1977) Aedes triseriatus and Aedes hendersoni: Vertical and temporal distribution as measured by oviposition. Envir Entomol 6:355-357

Service MW (1965) The ecology of the tree-hole breeding mosquitoes in the northern Guinea savanna of Nigeria. J Appl Ecol 2:1-16

Shroyer DA (1979) Seasonal aspects of egg hatching in Aedes triseriatus (Say): Sex ratio distortion and diapause. Ph D Thesis, University of Notre Dame: Notre Dame, Indiana

Sinsko MJ, Grimstad PR (1977) Habitat separation by differential vertical oviposition of two treehole Aedes in Indiana. Environ Entomol 6:485-487

Steel RGD, Torrie JH (1980) Principles and procedures of statistics. New York: McGraw-Hill

Steffan WA, Evenhuis NL (1981) Biology of Toxorhynchites. Ann Rev Entomol 26:159-181

Strong DR (1981) The possibility of insect communities without competition. In: Denno RF, Dingle H (eds) Insect life history patterns: Habitat and geographic variation. Springer: New York, pp 183-194

Tanaka K, Mizusawa K, Saugstad SS (1979) A revision of the adult and larval mosquitoes of Japan (including the Ryukyu Archipelago and the Ogasawara Islands) and Korea (Diptera: Culicidae). Contrib Amer Entomol Inst 16:1-987

Tate $\mathrm{P}$ (1932) The larval instars of Orthopodomyia pulchripalpis Rond. (Diptera Nematocera). Parasitol 24:111-120

Trimble RM, Smith SM (1979) Geographic variation in the effects of temperature and photoperiod on dormancy induction, development time, and predation in the tree-hole mosquito, Toxorhynchites rutilus septentrionalis (Diptera: Culicidae). Can J Zool 57:1612-1618

Truman JW, Craig GB (1968) Hybridization between Aedes hendersoni and Aedes triseriatus. Ann Entomol Soc Amer 61:1020-1025

Watts DM, Grimstad PR, DeFoliart GR, Yuill TM (1975) Aedes 
hendersoni: Failure of laboratory-infected mosquitoes to transmit LaCrosse virus (California encephalitis group). J Med Entomol 12:451-453

Zavortink TJ (1968) Mosquito studies (Diptera, Culicidae) VIII A prodrome of the genus Orthopodomyia. Contrib Amer Entomol Inst 3:1-221

Zavortink TJ (1970) Mosquito studies (Diptera, Culicidae) XIX. The treehole Anopheles of the New World. Contrib Amer Entomol Inst 5:1-35
Zavortink TJ (1972) Mosquito studies (Diptera, Culicidae) XXVIII. The New World species formerly placed in Aedes (Finlaya). Contrib Amer Entomol Inst 8:1-206

Zavortink TJ, Belkin JN (1979) Occurrence of Aedes hendersoni in Florida (Diptera, Culicidae). Mosq News 39:673

Received August 3, 1982 